\title{
Exercício físico em idosos: efeito nos biomarcadores periféricos de neuroproteção
}

\author{
Dissertação apresentada à Faculdade de Medicina \\ da Universidade de São Paulo para obtenção do \\ título de Mestre em Ciências
}

Programa de Ortopedia e Traumatologia

Orientador: Prof. Dr. Luiz Eugênio Garcez Leme

(Versão corrigida. Resolução CoPGr 5890, de 20 de dezembro de 2010.

A versão original está disponível na Biblioteca FMUSP)

São Paulo 


\section{LUCAS KÜHN PEREIRA PRADO}

\section{Exercício físico em idosos: efeito nos biomarcadores periféricos de neuroproteção}
Dissertação apresentada à Faculdade de Medicina da Universidade de São Paulo para obtenção do título de Mestre em Ciências

Programa de Ortopedia e Traumatologia

Orientador: Prof. Dr. Luiz Eugênio Garcez Leme

(Versão corrigida. Resolução CoPGr 5890, de 20 de dezembro de 2010.

A versão original está disponível na Biblioteca FMUSP)

São Paulo

2012 
Dados Internacionais de Catalogação na Publicação (CIP)

Preparada pela Biblioteca da

Faculdade de Medicina da Universidade de São Paulo

Creprodução autorizada pelo autor

\section{Prado, Lucas Kühn Pereira}

Exercício físico em idosos : efeito nos biomarcadores periféricos de neuroproteção / Lucas Kühn Pereira Prado. -- São Paulo, 2012.

Dissertação(mestrado)--Faculdade de Medicina da Universidade de São Paulo. Programa de Ortopedia e Traumatologia.

Orientador: Luiz Eugênio Garcez Leme.

Descritores: 1.Atividade motora 2.Doença de Alzheimer 3.PLA2 4.GSK3 5.Exercício 6.Idoso

USP/FM/DBD-094/12 
A meu pai Carlos Augusto, meu grande incentivador. 


\section{Agradecimentos}

A Deus pelo dom da vida e seus ensinamentos.

A toda minha família, pelo apoio incondicional e por compartilhar esta realização, em especial Cris, minha esposa e minha filhinha Mel, meus pais e irmãos : Uiramaia, Pondé, Daniella, Éneas, Clarinha, Uéslei e Rose.

Ao meu orientador, professor Garcez, que não foi apenas um excelente orientador, mas também um grande exemplo de vida, aprendi muito mais do que ciências médicas.

A todos os meus pacientes, pela colaboração, paciência e doação pela pesquisa. Em especial João Carreira e In memorian “José Moraes”.

A toda equipe do ambulatório do IOT, do LEM e da secretaria de pós-graduação.

Aos amigos da Geriatria pelas sugestões, correções e estímulos, em especial a turma do ambulatório de promoção de saúde e do GAMIA.

A toda equipe do LIM-27 da psiquiatria pela colaboração, em especial aos professores Leda e Gattaz. 


\section{Sumário}

Resumo

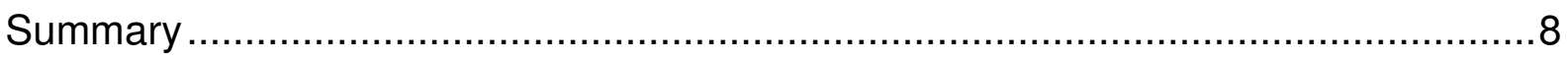

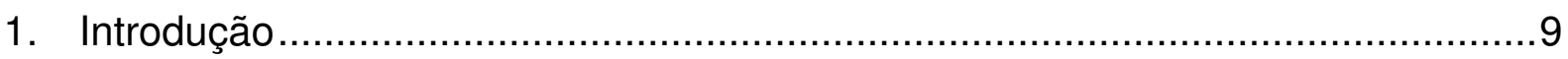

1.1. Atividade física e cognição ..................................................................11

1.1.1. Atividade física e prevenção de demência.............................................11

1.1.2. Efeitos Neuroprotetores da Atividade Física ......................................13

1.1.2.1. Atividade física e neurogênese .....................................................13

1.1.2.2. Atividade Física e inflamação .......................................................15

1.2. Biomarcadores periféricos de neuroproteção..........................................16

1.2.1. Glicogênio Sintase Quinase 3 beta (GSK3) ....................................16

1.2.1.1. GSK3, Inflamação e Doença de Alzheimer. ......................................17

1.2.1.2. Atividade Física e GSK3 ............................................................

1.1. Doença de Alzheimer ......................................................................19

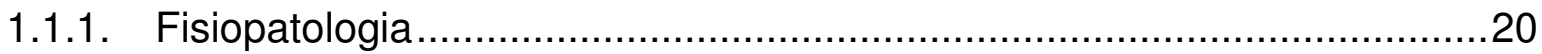

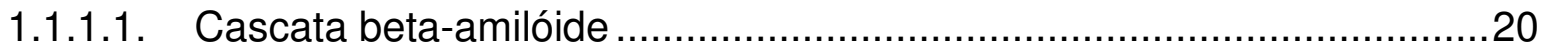

1.1.1.2. Emaranhado Neurofibrilares (EN) ..............................................23

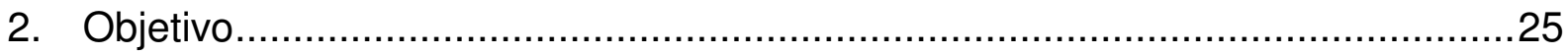

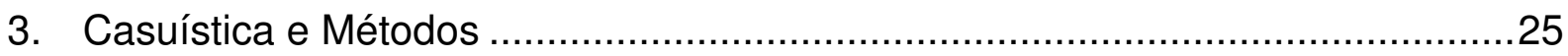

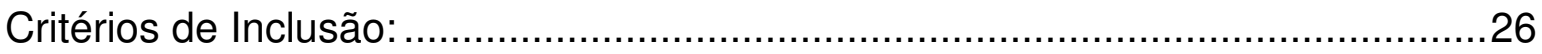

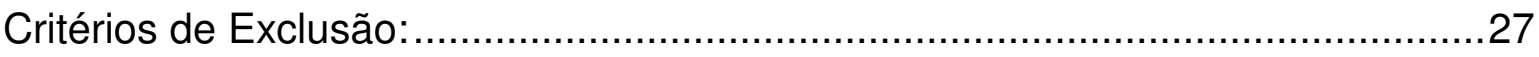




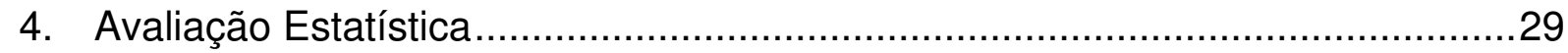

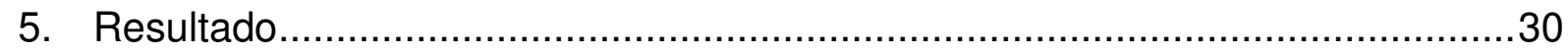

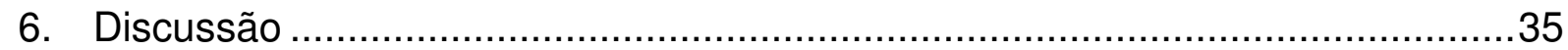

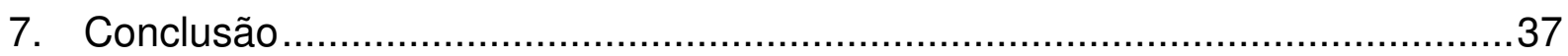

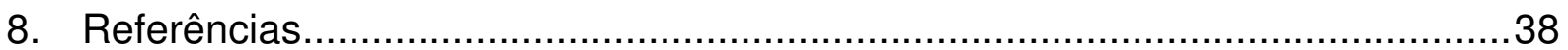

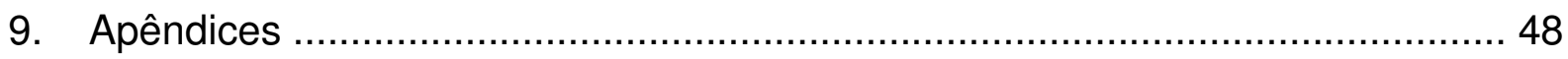




\section{Resumo}

PRADO, LKP. Exercício físico em idosos: efeito no biomarcador periférico de neuroproteção GSK3. São Paulo. Dissertação- Faculdade de Medicina da USP; 2012.

A atividade física (AF) demonstrou um efeito protetor contra a doença de Alzheimer (DA), mas não se sabe qual a influência da $A F$ sobre o biomarcador de neuroproteção, a glicogênio sintase-quinase 3 (GSK3). O Objetivo do nosso estudo é avaliar o efeito do exercício físico sobre os níveis séricos da GSK3. Foi realizado um estudo observacional de corte transversal, no qual 72 idosos saudáveis e sem demência foram selecionados e divido em dois grupos de acordo com o nível de atividade física. A atividade da GSK3 foi semelhante entre os grupos estudados, houve uma tendência a maior inativação da GSK3 (fator neuroprotetor) entre os ativos e maior ativação entre os sedentários e muito ativos, porém sem significância estatística. É possível que a atividade física de baixa intensidade já tenha um efeito protetor. Uma maior população de idosos e métodos mais precisos de mensurar AF serão necessários para demonstrar efeito da AF sobre a GSK3.

Palavras Chaves: atividade física, GSK3, Alzheimer, exercício, idosos 


\section{Summary}

PRADO, LKP. Physical activity in elderly: effect on peripheral biomarker of neuroprotection GSK3 (dissertation). São Paulo. "Faculdade de Medicina, Universidade de São Paulo", 2012.

The physical activity (PA) was demonstrated to have a protective effect against Alzheimer's disease, but the influence of exercising on the biomarker of neuroprotection such as Glycogen synthase kinase 3 (GSK-3) are hitherto imprecise. This study aims at assessing the effect of PA on the serum levels of GSK3. We have performed a cross-sectional observational study with 72 healthy elders, without dementia, selected and classified into two groups according to the level of PA. The GSK3 activity resulted similar in both groups; there was a tendency of inactivation of GSK3 (neuroprotective factor) among active elders and a higher activation among sedentary and highly active elders, although without statistical significance. It's possible that low-intensity physical activity may already have a protective effect. Further studies with higher number of participants and methods more accurate to measure PA will be needed to demonstrate effect of PA on the GSK3.

Key Words: physical activity,GSK3, Alzheimer, exercise. 


\section{Introdução}

O envelhecimento populacional aumentou de forma significativa nas últimas décadas. Uma projeção recente do IBGE ${ }^{1}$ (Instituto Brasileiro de Geografia e Estatística) prevê que a população de idosos vai triplicar até 2050 , passando dos atuais $10,8 \%$ para $29,7 \%$ da população total do país, correspondendo a quase 65 milhões. A expectativa de vida ao nascer aumentou para 73 anos na última década (1999 a 2009), entre as mulheres passou de 73,9 para 77 anos e entre os homens de 66,3 para 69 anos. Este envelhecimento da população brasileira trará um desafio cada vez maior para o SUS (Sistema Único de Saúde), pois os idosos apresentam um número maior de doenças crônicas, o que contribuem para perda da funcionalidade e declínio na qualidade de vida. A conseqüência é o aumento da demanda dos serviços públicos de saúde com maior número de internações hospitalares e uso de instituições de longa permanência ${ }^{2,3}$. O crescimento da população de idosos possivelmente ocasionará aumento significativo na prevalência das demências, síndrome de fragilidade e fraturas de colo de fêmur, doenças muito freqüentes nos países desenvolvidos.

A Doença de Alzheimer é a causa mais comum de doença neurodegenerativa. Em 2000 já acometia 4,5 milhões de norte-americanos e em 2050 haverá 13 milhões de portadores de Alzheimer nos EUA, elevando os custos da saúde, que hoje já variam de 18 a 36 mil dólares/ ano em média com os cuidados de um paciente dementado 4 . No Brasil, estima-se que 500 mil pessoas sejam acometidas pela doença de Alzheimer, a principal causa de demência, sendo responsável por 54 a $60 \%$ dos casos. Estudos populacionais transversais estimam uma prevalência de 7\% na população brasileira, que varia de $1,6 \%$ entre 65 a 69 anos a $38 \%$ nos acima de 85 $\operatorname{anos}^{5,6,7}$.

Frente ao aumento da população idosa são muito importantes medidas de promoção de saúde para reduzir a prevalência de doenças crônicas, melhorar a funcionalidade e controlar as multimorbidades. Busca-se a melhora da qualidade de vida na terceira idade e redução dos custos com saúde. Entre as medidas de promoção de saúde, a atividade física é uma das principais responsáveis, pelo controle das comorbidades, redução no risco de morbimortalidade por doenças cardiovasculares ${ }^{8}$, diabetes ${ }^{9}$, 
obesidade $^{10}$ e osteoporose ${ }^{11}$. É também relacionada à melhora da cognição ${ }^{12,13,14,15}$ e diminuição do risco de incidência da doença de Alzheimer ${ }^{16}$.

O exercício regular é importante para o envelhecimento saudável por influir nas doenças crônicas e na funcionalidade. Parece ser um fator protetor contra o envelhecimento genético e molecular, estando associado à longevidade ${ }^{17}$. Protege ${ }^{18}$ o organismo contra o estresse oxidativo ${ }^{19} \mathrm{e}$ a inflamação ${ }^{20}$, que são responsáveis por danos no ácido desoxirribonucleico (DNA) e em outras estruturas celulares com a perda progressiva das funções metabólicas e fisiológicas e maior propensão a doenças cardiovasculares, neurodegenerativas e oncológicas.

O entendimento dos fatores de risco e da fisiopatologia dos transtornos cognitivos é muito importante para o desenvolvimento de medidas efetivas de prevenção. Os principais fatores de risco estão bem definidos (idade, história familiar, hipertensão arterial sistêmica, diabetes, isolamento social, sedentarismo, depressão, etc. $)^{21}$ e a fisiopatologia bem caracterizada (acúmulo de proteínas amilóides, emaranhados neurofibrilares, neurodegradação, declínio dos neurotransmissores endógenos e da densidade das sinapses, aumento do dano neuronal oxidativo e do processo inflamatório no sistema nervoso central) ${ }^{22}$. Entretanto, o tratamento tem resultados muito limitados, baseando-se na modulação de neurotransmissores, com o uso de anti-colinesterásicos e moduladores glutamatergicos que tem resultado modesto sobre a evolução da doença. Deste modo, uma melhor compreensão dos mecanismos moleculares que promovem os efeitos preventivos da atividade física sobre os transtornos cognitivos é muito importante.

A pesquisa sobre biomarcadores é essencial na tentativa do diagnóstico precoce da doença de Alzheimer. Hoje o diagnostico é feito por questionários com testes cognitivos que classificam as fases iniciais como transtorno cognitivo leve (TCL), diagnóstico presente em cerca de $22-56 \%$ dos idosos. Estudos demonstraram que os indivíduos com TCL têm um risco maior de progressão para demência (6,7 maior que idosos saudáveis) e apresentam uma taxa de conversão de $10 \%$ ao ano para demência, porém muitos pacientes classificados como TCL evoluem com melhora do quadro ou apresentavam apenas transtorno do humor ${ }^{23}$. Desta forma 0 estabelecimento de biomarcadores é fundamental para uma melhor definição da 
fisiopatologia da DA. A GSK3 é um biomarcador que podem ajudar no diagnóstico precoce, favorecendo medidas preventivas e tratamento precoce. Parece-nos significante que definir o efeito da atividade física sobre os biomarcadores poderá ajudar a esclarecer a fisiopatologia da doença e aperfeiçoar medidas de prevenção.

Ainda existem dúvidas sobre como o exercício modula o estresse oxidativo e diminui os danos celulares associados ao envelhecimento. Não há trabalhos na literatura que avaliem o efeito da atividade física sobre a GSK3, e poucos trabalhos com BDNF (Fator Neurotrófico Cerebral) ${ }^{24,25}$, nenhum em idosos. Alguns trabalhos ${ }^{26,27,28}$ evidenciaram o efeito do exercício no aumento da expressão gênica de fatores antiinflamatórios e angiogênicos, porém nenhum trabalho avaliou especificamente expressão do GSK3 ou BDNF. O esclarecimento destas características fisiopatológicas é essencial para aumentar nossos conhecimentos sobre o tema e trazer novas perspectivas terapêuticas e comportamentais para uma longevidade mais saudável.

Este trabalho é um estudo transversal, que avaliará a influência da atividade física regular em idosos sobre uma substância relacionada à cognição e a doença de Alzheimer: a glicogênio sintase quinase três (GSK3). Objetiva esclarecer o efeito protetor do exercício sobre a memória e prevenção das demências.

\subsection{Atividade física e cognição}

\subsubsection{Atividade física e prevenção de demência}

O exercício físico já teve seus efeitos benéficos demonstrados na prevenção e controle das doenças cardiovasculares, osteomusculares, diabetes e até na prevenção de neoplasias. ${ }^{29}$ Nos últimos anos, as pesquisas têm focado nos efeitos benéficos da atividade física sobre o funcionamento cognitivo e a prevenção das demências. ${ }^{30}$

Alguns estudos prospectivos observacionais relacionaram a prática regular de atividade física em idosos com a prevenção e o retardo do declínio cognitivo. ${ }^{31,32,33}$ Um estudo prospectivo mostrou que idosos que praticavam atividade física regular 
três ou mais vezes por semana, tinham uma incidência $38 \%$ menor de doença de Alzheimer, em um seguimento de seis anos, quando comparado com um grupo semelhante de idosos com nível inferior de atividade física. ${ }^{34}$ Outro estudo de coorte avaliou a incidência de DA em 1880 idosos, com uma média de seguimento de 5,4 anos. Neste estudo além do nível de atividade física, também foi observado a aderência a dieta mediterrânea. Os idosos com maior nível de exercício apresentaram uma redução de risco de 33\% comparado aos sedentários. Quando associado alto nível de atividade física e boa aderência à dieta a redução de risco foi de $35 \%$ comparado aos sedentários com baixa aderência à dieta mediterrânea. ${ }^{35}$

Em 2008, um ensaio clínico com 170 idosos com problemas de memória, mas sem critérios para demência, avaliou os efeitos da atividade física sobre a cognição. Um dos grupos participou de um programa de atividade física de seis meses e o outro grupo foi acompanhado neste período por um programa educacional sem atividade física. Após um seguimento de 18 meses, o grupo exercício apresentou um melhor desempenho nos testes cognitivos. ${ }^{36}$

Em 2011, uma coorte avaliou a relação entre gasto energético total e a incidência de déficit cognitivo entre 197 idosos com boa funcionalidade e não dementados. O estudo usou a técnica de água duplamente marcada, que é um método de calorimetria indireta que mede com precisão o gasto energético total de indivíduos fora de confinamento, refletindo o nível de atividade física diário. Após seguimento de cinco anos foi observado uma menor incidência de declínio cognitivo (decréscimo de nove pontos no 3MS- Mini Exame do esta Mental modificado) no grupo com maior gasto enérgico comparado ao de menor gasto (OR 0,09, IC 0,01-0,79) ${ }^{37}$.

O nível de atividade física necessária para os ganhos cognitivos também não estão definidos, a maioria dos estudos demonstram benefícios com nível moderado de atividade física (4-6 METs), porém os questionários subestimam o gasto energético com atividade física do cotidiano. Outros estudos ${ }^{38,39}$ que avaliam longevidade, identificaram maior sobrevida entre indivíduos com atividade física intensa (corredores, $\geq 6$ METs) , quando comparado a exercícios de moderada e baixa intensidade, este efeito seria explicado pela diminuição do risco cardiovascular (controle pressórico, diminuição da resistência insulínica, melhora no perfil lipídico). 
Por outro lado, o exercício muito intenso (ultramaratonistas, corredores $>64 \mathrm{KM}$ por semana) apresentam um maior número de lesões osteoarticulares e imunossupressão. Não sabemos qual o nível ideal de atividade física para os benefícios cognitivos, modulação dos neuroprotetores e da atividade inflamatória. Nosso grupo é formado por idosos atletas corredores, praticantes de atividade física de forte intensidade (média 300 minutos/semana de corrida), permitindo talvez um menor número de participantes para demonstrar os efeitos do exercício.

Apesar de inúmeros trabalhos mostrando os benefícios da atividade física sobre a cognição e prevenção de demências, ainda não está bem esclarecido quais os mecanismos deste efeito protetor.

\subsubsection{Efeitos Neuroprotetores da Atividade Física}

A influência da atividade física na neurogênese, nos neurotransmissores, na vasculatura cerebral e na modulação da inflamação e do sistema imunológico são os principais fatores relacionados aos seus efeitos neuroprotetores. ${ }^{40}$

\subsubsection{Atividade física e neurogênese}

Está bem estabelecido que o cérebro de mamíferos adultos pode produzir novos neurônios. Células neurológicas recém-nascidas foram encontradas no bulbo olfatório, hipocampo e no giro denteado ${ }^{41,42}$. A neurogenêse em adultos pode ser modulada por vários fatores, como estresse, envelhecimento, estímulo ambiental e atividade física. ${ }^{43}$ Os estímulos cognitivos (estímulo ambiental, leitura) reforçam a neurogênese no hipocampo e no bulbo olfatório, os estímulos olfatórios interferem apenas no bulbo olfatório, enquanto a atividade física aumenta a neurogênese no hipocampo. O exercício pode minimizar os efeitos negativos que o envelhecimento e as doenças neurodegenerativas tem sobre o hipocampo. ${ }^{44}$ Estudos em roedores observaram que o envelhecimento é um dos principais fatores relacionados a diminuição da neurogênese hipocampal ${ }^{45,46}$. É possível que a exposição crônica a níveis aumentados de corticóides influencie negativamente a neurogênese hipocampal no envelhecimento ${ }^{47}$. A atividade física em animais idosos reverte o declínio da proliferação celular, entretanto não mantém a neurogênese no mesmo nível que em animais jovens ${ }^{53}$. 
Alguns estudos em roedores demonstraram que a atividade física não só aumenta o número de neurônios no hipocampo, como também influencia positivamente a morfologia neuronal. ${ }^{48,49,50} \mathrm{~A}$ neurogênese está associada a um aumento da plasticidade sináptica no hipocampo, influenciando o potencial de longa duração (PLD) e beneficiando a memória e o aprendizado. ${ }^{51}$

O efeito da atividade física sobre os neurotransmissores, os fatores de crescimento celular e vascular são os prováveis responsáveis pelo aumento da neurogênese ${ }^{48}$. O exercício ativa os genes glutamatérgicos no hipocampo de roedores e inibe os do sistema gabaérgico .0 sistema glutamatérgico regula a neurogênese e aumenta a plasticidade neuronal nos neurônios recém-nascidos ${ }^{52,53}$.Estudo feito em camundongos, mostrou que após um mês de corrida regular, os níveis de mRNA (RNA mensageiro) do receptor glutamatérgico e a expressão gênica do fator neurotrófico cerebral (BDNF) aumentaram especificamente no hipocampo. ${ }^{54}$

A atividade física também aumenta a produção de neurotransmissores, como a serotonina, que está envolvida na fisiopatologia dos transtornos do humor. Já foi demonstrado o efeito do exercício no tratamento das depressões, sendo tão efetivo como o uso de medicações serotoninérgicas. ${ }^{55} \mathrm{~A}$ influência da serotonina e de outros neurotransmissores na neurogênese parece ser uma via importante no tratamento da depressão ${ }^{56}$.

Fatores tróficos, como o BDNF, o fator de crescimento insulina símile 1 (IGF-I) e o fator de crescimento endotelial (VEGF) são importantes sinalizadores na diferenciação e proliferação celular, influenciando diretamente a neurogênese.$^{57} \mathrm{O}$ exercício aumenta a expressão gênica tanto do BDNF, como também de fatores tróficos vasculares como o VEGF e o IGF-1, aumentando a angiogênese cerebral e facilitando a proliferação celular ${ }^{57}$. Um estudo de neuroimagem com ressonância nuclear magnética (RNM) em humanos e camundongos mostrou uma correlação entre o fluxo sanguíneo no giro denteado e a neurogênese, sugerindo que a perfusão vascular pode ser um bom indicador de neurogênese em humanos. ${ }^{58}$ Outra pesquisa observou que o exercício voluntário em camundongos aumentou a área e o perímetro dos vasos no giro denteado, porém este efeito benéfico só foi observado nos animais jovens ${ }^{48}$. 


\subsubsection{Atividade Física e inflamação}

A desregulação do sistema inflamatório está relacionado à perda cognitiva e a doença de Alzheimer, estudos demonstram um nível elevado de citocinas inflamatórias, como TNF- $\alpha$ e IL-1, no sangue e no tecido cerebral de pacientes com $\mathrm{DA}^{61}$.

A produção aumentada de IL-1 $1 \beta$ está relacionado a expressão gênica da proteína beta-amilóide, formação de placas senis e emaranhados neurofibrilares, principais marcadores histológicos da DA. As células de defesa do tecido cerebral, a micróglia e os astrócitos também se encontram mais reativos nos pacientes com DA ${ }^{59}$. A GSK3 é um importante mediador pró-inflamatório deste processo, ela ativa o fator de fator nuclear de transcrição $k \beta$ ( NF- $k \beta$ ), responsável pela produção de citocinas inflamatórias como IL-1 e TNF ${ }^{61}$.

Um dos efeitos benéficos da atividade física sobre a cognição seria pela modulação do sistema inflamatório. Este fenômeno seria explicado pela teoria de "Hormesis"60: a observação de que a exposição repetida de pequenas doses de toxinas e/ou radiação pode trazer benefícios aos organismos expostos, através de mudanças adaptativas. Por exemplo, restrição calórica e consumo moderado de álcool em animais experimentais promoveram prevenção de doenças e longevidade.

O efeito agudo do exercício provoca dano tecidual, aumento de radicais livres e inflamação. A produção de espécies reativas do oxigênio (radicais livres) são produtos do metabolismo aeróbico e importantes na resposta inflamatória, na sinalização entre as células, na defesa contra as bactérias, na indução da apoptose e na estimulação do sistema de reparo celular e anti-oxidante. Por outro lado a produção exagerada de radicais livres está relacionado a fisiopatologia das doenças cardiovasculares, do câncer e das doenças neurodegenerativas, como a DA ${ }^{58}$.

A longo prazo, doses repetidas de atividade física provocam um aumento de antioxidantes e redução dos níveis de citocinas pró-inflamatórias como a TNF, além de estimular a expressão de citocinas anti-inflamatórias como $\mathrm{IL}-6$ e $\mathrm{IL}-10^{57}$. Deste modo, o exercício estimula o sistema de reparo celular e aumenta a atividade do complexo proteosoma, responsável por degradar as proteínas danificadas pela 
resposta inflamatória, como, por exemplo, a beta-amilóide. Além disso o sistema de reparo do DNA também é otimizado pela pratica regular de atividade física ${ }^{58}$.

\subsection{Biomarcadores periféricos de neuroproteção}

\subsubsection{Glicogênio Sintase Quinase 3 beta (GSK3)}

A GSK3 é uma enzima distribuída em vários tecidos (sistema nervoso central, trato gastrointestinal, células do sistema imunológico, tecido muscular, etc) e que atua sobre mais de cinqüenta substratos (enzimas, fatores de transcrição gênica, hormônios, citocinas) ativando os mesmos através da fosforilação, sendo envolvida em muitos processos celulares: o metabolismo do glicogênio (inibindo formação de glicogênio e aumentando resistência a insulina), na transcrição gênica, na apoptose e na inflamação. Esta atividade ampla de ação faz com que esta enzima seja relacionada à fisiopatologia de muitas doenças, como a diabetes, o câncer, os transtornos neuropsiquiátricos (depressão e transtorno bipolar do humor) e as doenças neurodegenerativas. A modulação positiva sobre a cascata inflamatória e seus efeitos neurotóxicos seriam responsáveis pela fisiopatologia da DA ${ }^{61}$

A atividade desta enzima é regulada de diversas formas - quatro mecanismos são mais conhecidos:

1- A fosforilação da GSK3 na posição do aminoácido serina-9 é um importante mecanismo inibitório. Várias enzimas regulam a GSK3 desta forma, entre elas a insulina, através de sua via de sinalização intracelular (PI3K/Aktsinalizadores), esta inibição aumenta a produção de glicogênio e modula negativamente a atividade inflamatória. Outras enzimas como os fatores de crescimento (Fator de crescimento epidermal e fibroblástico) e proteínoquinases $\mathrm{A}$ e $\mathrm{C}$ também inibem por esta via, gerando efeitos sobre $\mathrm{O}$ ciclo celular, apoptose e na gênese de células cancerígenas ${ }^{62}$.

2- A ação da GSK3 também é modulada por sua localização intracelular, dentro do núcleo e na mitocôndria está muita ativa, enquanto nos neurônios em crescimento tem baixa atividade ${ }^{61}$. 
3- A formação de complexo intracelular com outras proteínas (cdc42 e par6, proteínas envolvidas na migração celular e endocitose) desativa a GSK3. Esta forma de modulação impede a ação da GSK3 sobre a beta-catenina, enzima envolvida na aderência celular e na oncogênese.

4- A ação da GSK3 sobre seus substratos depende de uma pré-fosforilação dos substratos, exigindo uma coordenação temporal na atividade das proteíno quinases para ativação da GSK.

Descreveremos abaixo as ações da GSK3 sobre o sistema inflamatório e a fisiopatologia da doença de Alzheimer, assuntos relacionados à nossa pesquisa.

\subsubsection{GSK3, Inflamação e Doença de Alzheimer.}

A GSK3 é fator determinante do processo inflamatório, estimula várias citocinas próinflamatórias, como a interleucina-6 (IL-6), o fator de necrose tumoral (FNT) e a interleucina $1 \beta$ (IL $1 \beta$ ) e diminui a produção de citocinas anti-inflamatórias como a IL-10. Além de estimular vários receptores de monócitos e células inflamatórias no sangue periférico, influenciando a migração celular. Esta ação da GSK3 é feita através da ativação do fator nuclear de trasncrição $\kappa \beta$ ( NF- $\kappa \beta)$, responsável pela produção das citocinas acima referidas. A administração de inibidores da GSK3 protege contra choque por endotoxinas em camundongos ${ }^{63}$.

A inflamação é uma função essencial do sistema imunológico, responsável pela proteção contra patógenos e reparação de danos celulares traumáticos, isquêmicos e neurodegenerativos. Porém, o desequilíbrio deste sistema está relacionado a várias condições patológicas. No sistema nervoso central (SNC), a barreira hematoencefálica protege o tecido neuronal das respostas inflamatórias sistêmicas, limitando a penetração de mediadores inflamatórios periféricos. A micróglia, por outro lado, funciona como um macrófago no SNC, coordenando a resposta imune. Várias agressões, como isquemia, trauma, infecção e doenças neurodegenerativas ativam a microglia, aumentam a migração celular para os locais afetados e a produção de citocinas inflamatórias e fatores de crescimento para regeneração neuronal. Este efeito agudo é benéfico, entretanto a resposta inflamatória crônica 
provoca dano neuronal e apoptose. Este fenômeno está associado às doenças neurodegenerativas, como a doença de Alzheimer ${ }^{64,65}$.

Vários mecanismos patológicos ligam a atividade da GSK3 à DA:

- A hiperexpressão da GSK3 em camundongos evita a indução do potencial de longa duração e diminui o aprendizado espacial, efeito revertido por inibidores da GSK. Várias enzimas envolvidas no processo da memorização são moduladas pela GSK3, entre elas a cAMP, um modulador positivo da memória que é inibido quando fosforilado pela GSK3. ${ }^{66}$

- GSK3 é a principal enzima responsável pela fosforilação da Tau (proteína estabilizadora do citoesqueleto dos neurônios) e formação dos emaranhados neurofibrilares (EN), marcadores histológicos de neurodegeneração na DA. Estudos em camundongos transgênicos com hiperexpressão de GSK3 mostraram que o tratamento com lítio, inibidor da GSK3, previne a formação de EN, embora não diminui os já formados ${ }^{67}$.

- A exposição dos neurônios à beta-amilóide aumenta a atividade da GSK3, amplificando a neurodegeneração. A sinalização da insulina, modulador negativo da GSK3, exerce efeito benéfico sobre a PPA (proteína precursora amilóide), aumenta a expressão da beta amilóide protease e a secreção da forma não amiloidogênica da $\mathrm{PPA}^{68}$. Estudos em humanos demonstraram que insulina intranasal melhora 0 desempenho cognitivo ${ }^{69}$.

- A inflamação crônica também é um fator associado à DA. A micróglia e os mediadores inflamatórios se acumulam em torno das placas senis. A GSK3 é muito importante na modulação da resposta inflamatória periférica, porém pouco é sabido sobre a modulação da GSK3 na resposta inflamatória no $\mathrm{SNC}^{70}$.

Existem evidências substanciais que a GSK3 é parte da fisiopatologia da DA, estudos mostram aumento da atividade desta enzima em hipocampo de pacientes com DA e até aumento na atividade da GSK3 no sangue periférico (linfócitos) de pacientes com transtorno cognitivo leve e DA comparados com controles saudáveis ${ }^{71}$. Nenhum dado relaciona o efeito da atividade física sobre a ação desta enzima. 


\subsubsection{Atividade Física e GSK3}

Não há dados na literatura que avaliem o efeito da atividade física sobre a GSK3, porém o exercício funciona na prevenção da doença de Alzheimer e da diabetes, morbidades associadas a desregulação na atividade da GSK3.

A atividade física tem efeitos positivos sobre a ação da insulina, diminuindo a resistência periférica e otimizando a ação deste hormônio. Desta forma o exercício modularia a atividade da GSK3 através da insulina, evitando a hiperexpressão, já que a insulina inibe a GSK3.

A atividade física também modula o sistema inflamatório, reduzindo produção de citocinas pró-inflamatórias, como IL1 e TNF, e aumenta a produção da IL10 (interleucina 10), citocina anti-inflamatória. A ativação da IL10 seria outra via de inibir a ação da GSK3, que é responsável pelo aumento na atividade das citocinas inflamatórias.

\subsection{Doença de Alzheimer}

A Doença de Alzheimer foi descrita pela primeira vez em 1907, quando o médico alemão Alois Alzheimer relatou o caso de uma senhora de 51 anos que evoluiu com perda progressiva de memória, linguagem e alteração comportamental, falecendo 4,5 anos após o diagnóstico com demência avançada. Na época, foram descritos os achados anatomopatológicos, caracterizando-se por acumulo de placas senis nos espaços extra-celulares e lesões neurofibrilares no interior dos neurônios, distribuídas difusamente por todo cérebro. Pouco tempo depois, Oscar Fisher descreveu cérebros de idosos dementados que possuíam os mesmos achados patológicos. Estes últimos achados foram considerados normais do envelhecimento e durante muitas décadas esta síndrome foi descrita como demência senil ${ }^{72,73 .}$

Nos anos seguintes, com o envelhecimento populacional, a prevalência da demência senil começou aumentar e retornaram os questionamentos sobre a fisiopatologia Seria normal do envelhecimento cerebral ou não? Pacientes dementados com idade inferior a 65 anos teriam doença de Alzheimer, enquanto os mais idosos não? Em 
1976, Katzman definiu: "Doença de Alzheimer e demência senil possuem a mesma fisiopatologia e devem ser consideradas a mesma doença" 74 .

Atualmente, a doença de Alzheimer é a forma mais comum de demência em idosos e acomete até $50 \%$ dos nonagenários ${ }^{75,76}$. A síndrome de acordo com o padrão genético é dividida em três subtipos ${ }^{77}$ :

1- De início tardio ou esporádico, associado ao alelo ApoE4 e mais comum, onde o quadro clínico se inicia comumente após os 65 anos.

2- De início precoce, familiar, de herança autossômica dominante, devido a mutações nos genes da presenilina 1 e 2 , acometendo paciente tipicamente entre 40 e 50 anos.

3- Associado a síndrome de Down, no qual a trissomia do gene 21 aumenta a produção da beta-amilóide, os pacientes geralmente desenvolvem o quadro demencial entre 40 e 70 anos.

\subsubsection{Fisiopatologia}

Os dois principais achados neuropatológicos da DA são as placas senis e os emaranhados neurofibrilares, associados à diminuição do volume cerebral, do número de neurônios, do número de sinapses e da extensão das ramificações dendríticas. Estas alterações também ocorrem no envelhecimento cerebral normal, porém com maior intensidade em indivíduos com Alzheimer ${ }^{78}$.

\subsubsection{Cascata beta-amilóide}

As placas extra-celulares são formadas por acúmulo de uma proteína precursora, chamada beta-amilóide, associada a neurônios degenerados (terminais de axônios e dendritos distendidos) e envolvidas por células microgliais e astrócitos. Estas placas são encontradas difusamente pelo neocórtex, com comprometimento maior do lobo frontal e na porção medial e basal do lobo temporal (hipocampo), poupando, inicialmente, áreas sensitivas e motoras primárias ${ }^{79,80}$. 
A proteína precursora amilóide (PPA) é uma proteína trans-membrana (grande parte voltada para o meio extracelular e uma pequena parte no citosol), de função ainda desconhecida. Porém pesquisa com camundongos "Knock out" para o gene da PPA mostraram apresentação precoce de gliose, sugerindo que a PPA é necessária para bom desenvolvimento neuronal, adesão e movimento celular ${ }^{81}$.

A Proteína beta-amilóide, principal componente das placas senis, é originada da endoproteólise da PPA. A clivagem da PPA pode ser dividida em amiliodogênica e não amiliodogênica, dependendo da seqüência da proteólise pelo grupo de enzimas alfa, beta e gama-secretases. Na via prevalente, não amiliodogênica, a PPA é clivada pela alfa-secretase, seguida nova clivagem pela gama-secretase, gerando a sPPAa (Proteína precursora amilóide alfa solúvel) que parece agir como um fator trófico. A via amiliodogênica é uma via alternativa e menos comum, onde a clivagem da PPA é realizada pela beta secretase, seguida pela gama-secretase, gerando a proteína beta amilóide. A liberação do fragmento beta-amilóide no espaço extracelular é seguido por agregação, formação de depósitos fibrilares insolúveis de amilóides resistentes a degradação enzimática, formando as placas senis e causando danos neuronais ${ }^{82,83}$.

Um estudo demonstra que há uma produção intracelular de beta-amilóide, que estaria relacionada à disfunção nas sinapses, nos proteosomas e facilitaria a fosforilação da proteína tau. Nos cérebros de pacientes no estágio inicial da doença de Alzheimer haveria maior acumulo de beta-amilóide intraneuronal, que se tornariam extracelulares com a progressão da doença e a morte neuronal. A betaamilóide intracelular pode se encontrar na forma monomérica, solúvel e não tóxica e na forma oligomérica, que pode agregar-se e causar danos celulares. Treinos cognitivos em ratos aumentam a concentração da forma solúvel e reduzem as formas oligoméricas e as placas extra-celulares. Outros fatores associados a doença de Alzheimer também aumentam a concentração da beta-amilóide intracelular, como os hormônios do stress, dieta rica em colesterol, estresse oxidativo, presença do alelo ApoE4. É descrito que os indivíduos jovens são mais capazes de neutralizar os efeitos tóxicos da proteína beta-amilóide intracelular ${ }^{84}$. 
Muitas evidências sugerem a via da beta-amilóide como principal fator responsável pela fisiopatologia da doença de Alzheimer (DA), mas algumas questões ainda não estão esclarecidas. Entre os muito idosos a presença de placas senis não é capaz de diferenciar dementados de idosos com cognição preservada, pois há um aumento do deposito de placas senis com o envelhecimento, nem sempre associado ao desenvolvimento da síndrome demencial. Além disso, 10\% dos pacientes com diagnóstico clínico de DA não preenchem critérios histopatológicos, ou seja, apresentam poucas placas senis. Existem, em alguns casos, divergências entre 0 diagnóstico clínico e histopatológico, há pacientes com déficits cognitivos leves que não preenchem critérios clínicos para DA e já possuem lesões histológicas compatíveis com DA e alguns destes indivíduos vão morrer sem desenvolver demência. Outras demências não Alzheimer também são classificadas histopatologicamente como $\mathrm{DA}^{96}$.

As placas senis também são observadas na demência por corpúsculo de Lewy, em pacientes após traumatismo craniano, na epilepsia do lobo temporal, doenças cerebrovasculares e em idosos não dementados como já foi discutido. Um estudo em centenários demonstrou que se forem definidos diagnósticos apenas histológicos 95\% dos idosos teriam achados mínimos de DA pelos critérios CERAD e Khachaturian ${ }^{85}$. Outro estudo histopatológico com cérebro de 159 idosos acima de 85 anos, demonstrou que todos apresentavam no mínimo achados leves de DA ${ }^{86}$.

Estas observações indicam a necessidade de um melhor esclarecimento da fisiopatologia da DA. O que é mais importante, o diagnóstico histológico ou clínico? A Doença de Alzheimer faz parte do envelhecimento cerebral?

A cascata amilóide foi desenvolvida e embasada em estudos com a forma familiar da DA. Talvez a forma esporádica e mais comum da DA não seja simplesmente conseqüência da amiloidose primária.

Um estudo prospectivo recente, com nove anos de observação, avaliou a relação dos níveis plasmáticos da beta-amilóide e a incidência de declínio cognitivo em quase mil idosos, e demonstrou que o percentil com menor nível plasmático de betaamilóide 42/40 apresentou maior declínio cognitivo durante a observação, porém esta relação foi mais forte nos indivíduos com baixa reserva cognitiva (conceito 
diretamente relacionado a o grau de escolaridade e nível de alfabetização). Pacientes com baixa escolaridade e agrupados no percentil mais baixo de betaamilóide 42/40 no sangue periférico tiveram uma perda de 8,9 pontos em um teste cognitivo global denominado Mini-Exame do Estado Mental Modificado (3MS), comparada a uma perda de 4,6 pontos entre os indivíduos com segundo grau completo. Este trabalho traz o conceito da reserva cognitiva como outra variável que influenciaria na manifestação clínica da DA, justificando, talvez, os casos com discordância clínica-histopatológica. Os indivíduos com boa reserva cognitiva necessitariam de mais lesões amilóides para apresentar quadro demencial do que indivíduos com baixa reserva cognitiva ${ }^{87}$.

\subsubsection{Emaranhado Neurofibrilares (EN)}

Os emaranhados neurofibrilares são outro achado neuropatológico da DA. São encontrados no citoplasma dos neurônios, formados pelo acúmulo de filamentos pareados helicóides de proteínas, principalmente a proteína tau. Esta proteína tem a função de estabilizar o citoesqueleto celular, liga-se aos microtúbulos (MT), mantendo morfologia apropriada dos neurônios e permitindo um eficiente transporte de substâncias e organelas pelo axônio. Em condições fisiológicas, a proteína tau está em constante equilíbrio dinâmico com os microtúbulos, ligadas e não ligadas a eles. Este equilíbrio é modulado pelas enzimas quinases e fosfatases, que controlam a fosforilação da proteína tau. Frequentes ciclos de ligação (fosforilação-quinase) e desligamento (desfosforilação-fosfatase) da tau dos microtúbulos são necessários para um efetivo transporte neuronal ${ }^{88}$.

Os emaranhados neurofibrilares são conseqüência do desligamento anormal da proteína tau dos microtúbulos, gerado pela hiperfosforilação da tau, por excesso de atividade das quinases ou redução da atividade das fosfatases. Estas alterações patológicas podem ser ocasionadas por mutações genéticas, como a mutação do gene tau (MAPT) causando demência frontotemporal (DFT) com parkinsonismo ligado ao cromossoma 17, ou por desequilíbrio na atividade das quinases e fosfatases. Algumas quinases, como a glicogênio quinase-sintase três (GSK3), já são estudadas como alvo terapêutico para DA. A inibição da GSK3 pelo lítio, in vivo, 
reduz a fosforilação da proteína tau e diminui a agregação protéica para formação dos emaranhados ${ }^{89,90}$.

O estresse oxidativo e a inflamação também podem ocasionar a hiperfosforilação da proteína tau e contribuir para a desestabilização dos microtúbulos, entretanto já foi demonstrado que a tau patológica pode interferir na função mitocondrial e induzir estresse oxidativo. Ou seja, embora o estresse oxidativo possa desencadear 0 processo patológico da tau, também é possível que a tau patológica amplifique este efeito $^{91}$.

A ligação entre a toxicidade amilóide e os emaranhados neurofibrilares ainda não está esclarecida. Estudo com neurônios hipocampais de camundongos "tauknockout" mostrou que estas células foram resistentes a toxicidade beta-amilóide, porém a supressão prolongada da tau foi associada alterações comportamentais e anormalidades estruturais durante o envelhecimento dos camundongos ${ }^{96}$.

A neurodegeneração provocada pelos EN é conseqüência da perda da função estrutural do citoesqueleto, comprometendo o transporte axonal, gerando disfunção sináptica e morte neuronal. Além da perda de função dos microtúbulos os EN também têm função tóxica, seqüestrando mais tau e outras proteínas e amplificando a perda de função normal da tau, contribuindo com a evolução da perda cognitiva. Estudos imunohistoquímicos demonstraram que o número de $\mathrm{EN}$ em determinadas regiões do cérebro de pacientes com doença de Alzheimer tem relação com o grau de perda cognitiva, ao passo que esta relação não ocorre com as placas senis ${ }^{92}$.

Outros estudos demonstraram que na fase inicial da neurodegeneração ocorrem defeitos no transporte axonal, perda sináptica e neuroinflamação, ocasionados apenas pela hiperfosforilação da tau e que os EN representariam uma fase tardia da doença e seriam responsáveis por sua progressão ${ }^{93,94}$.

Os EN não são característicos apenas da DA, aparecendo também na DFT e em outras doenças neurodegenerativas, como a paralisia supranuclear progressiva e a degeneração corticobasal. Embora, os EN sejam melhores marcadores da perda cognitiva do que as placas senis, eles também são encontrados em idosos não dementados. O depósito de EN começa na terceira década e aumenta com a idade. 
Seria um marcador de envelhecimento neuronal? Neste contexto, os pacientes com mais depósitos de EN e menor reserva cognitiva teriam maior chance de desenvolver quadros demenciais ${ }^{95,96}$.

\section{Objetivo}

O objetivo do presente trabalho é avaliar o efeito da atividade física em idosos no nível sanguíneo do marcador periférico de neuroproteção GSK3.

\section{Casuística e Métodos}

Este trabalho é um estudo observacional de corte transversal, controlado, com seleção aleatória e não-randômica de uma amostra de 74 homens (maiores de 60 anos) realizado no Instituto de Ortopedia da Faculdade de Medicina da Universidade de São Paulo (IOT-FMUSP), em parceria com o Laboratório de Neurociências (LIM 27) do Instituto de Psiquiatria (IPQ) e o Serviço de Geriatria da FMUSP.

O tamanho da amostra foi baseado em trabalhos internacionais relacionados ao efeito da atividade física sobre marcadores do estresse oxidativo ${ }^{97,98}$ e aos trabalhos relacionados às substâncias estudadas. Trabalho recente de Talib $^{77}$ et al. demonstrou o efeito positivo do treino cognitivo sobre a atividade da PLA2 em um grupo de 23 pacientes.

Setenta e quatro idosos foram selecionados nos ambulatórios do IOT-FMUSP e do Serviço de Geriatria durante o ano de 2009, todo paciente respondeu a um questionário (abaixo) que avaliou a funcionalidade, o desempenho cognitivo, o nível de atividade física e as comorbidades e foi selecionado para a pesquisa seguindo os critérios de inclusão . 
Questionário de Avaliação (anexo 3)

1. Idade/Sexo

2. Comorbidades (HAS, diabetes, dislipidemia, doença coronariana, insuficiência cardíaca, doença vascular periférica, hepatopatia, doença pulmonar obstrutiva crônica, acidente vascular cerebral).

3. Índice de Massa Corpórea (IMC).

4. História de tabagismo, os grupos foram divididos em: fumantes, ex-fumantes e não-fumantes.

5. Nível sócio-econômico, definido pela renda familiar, quantificada em múltiplos do salário mínimo de então ( $R \$ 465,00$ / US \$ 199,00).

6. Avaliação cognitiva para detectar casos de demência, utilizando o Mini-Exame do Estado Mental (MEEM) ${ }^{99}$ ( anexo 4).

7. Auto avaliação do bem-estar e saúde (classificada como ótimo, bom, regular e ruim).

8. Avaliação do humor, através da Escala de Depressão Geriátrica - versão

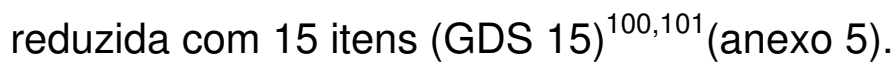

9. Avaliação do nível de atividade física, utilizando o Questionário Internacional de Atividade Física- versão curta (IPAQ) ${ }^{102}$ (anexo 7).

\section{Critérios de Inclusão:}

1. Idade maior ou igual a 60 anos.

2. Pacientes sem limitação funcional para atividades básicas (ABVD) ${ }^{103}$ (anexo 1) e instrumentais da vida diária (AIVD) ${ }^{104}$ (anexo 2). 
3. Não portadores de doenças neurodegenerativas (demência, doença de Parkinson, esclerose lateral amiotrófica) e neoplasias (exceto câncer de pele não-melanoma e câncer de próstata não avançado).

4. Pontuação no Mini Exame do Estado Mental(MEEM) maior que 24.

5. Sem comorbidades descompensadas que alterassem a funcionalidade.

6. Auto-percepção da saúde boa ou ótima.

7. Aceitação e preenchimento do termo de consentimento.

\section{Critérios de Exclusão:}

1. Solicitação do paciente para sair da pesquisa

2. Perdas de dados do paciente, não recuperáveis.

Após esta avaliação inicial dois idosos foram afastados da pesquisa devido ao baixo desempenho no teste cognitivo (MEEM<24).

Os setenta e dois pacientes foram divididos em dois grupos, de acordo com o nível de atividade física, baseado no Questionário Internacional de Atividade Físicaversão curta (IPAQ) (Anexo 7). Foi definido como grupo sedentário o dos pacientes classificados no IPAQ com sedentários e insuficientemente ativos e como grupo de atletas os pacientes classificados como ativos e muito ativos.

\section{Grupos da pesquisa:}

1. Atletas - 41 idosos corredores ou praticantes de atividade física resistida, que estavam no mínimo há um ano em treinamento, numa freqüência maior ou igual duas vezes por semana. Estes pacientes foram recrutados no ambulatório de idosos corredores do Instituto de Ortopedia da FMUSP e do grupo de atividade física resistida do Laboratório de Estudo do Movimento (LEM) do Instituto de Ortopedia da FMUSP. 
2. Sedentários - 31 idosos que não praticavam atividade física regular (freqüência mínima de duas vezes por semana). Estes pacientes foram recrutados no ambulatório de promoção de saúde do Serviço de Geriatria da FMUSP.

Os participantes selecionados foram encaminhados ao Laboratório de Neurociências ( LIM 27) do Instituto de Psiquiatria da USP para coleta de sangue e dosagem dos biomarcadores.

\section{Diagrama resumo da casuística}

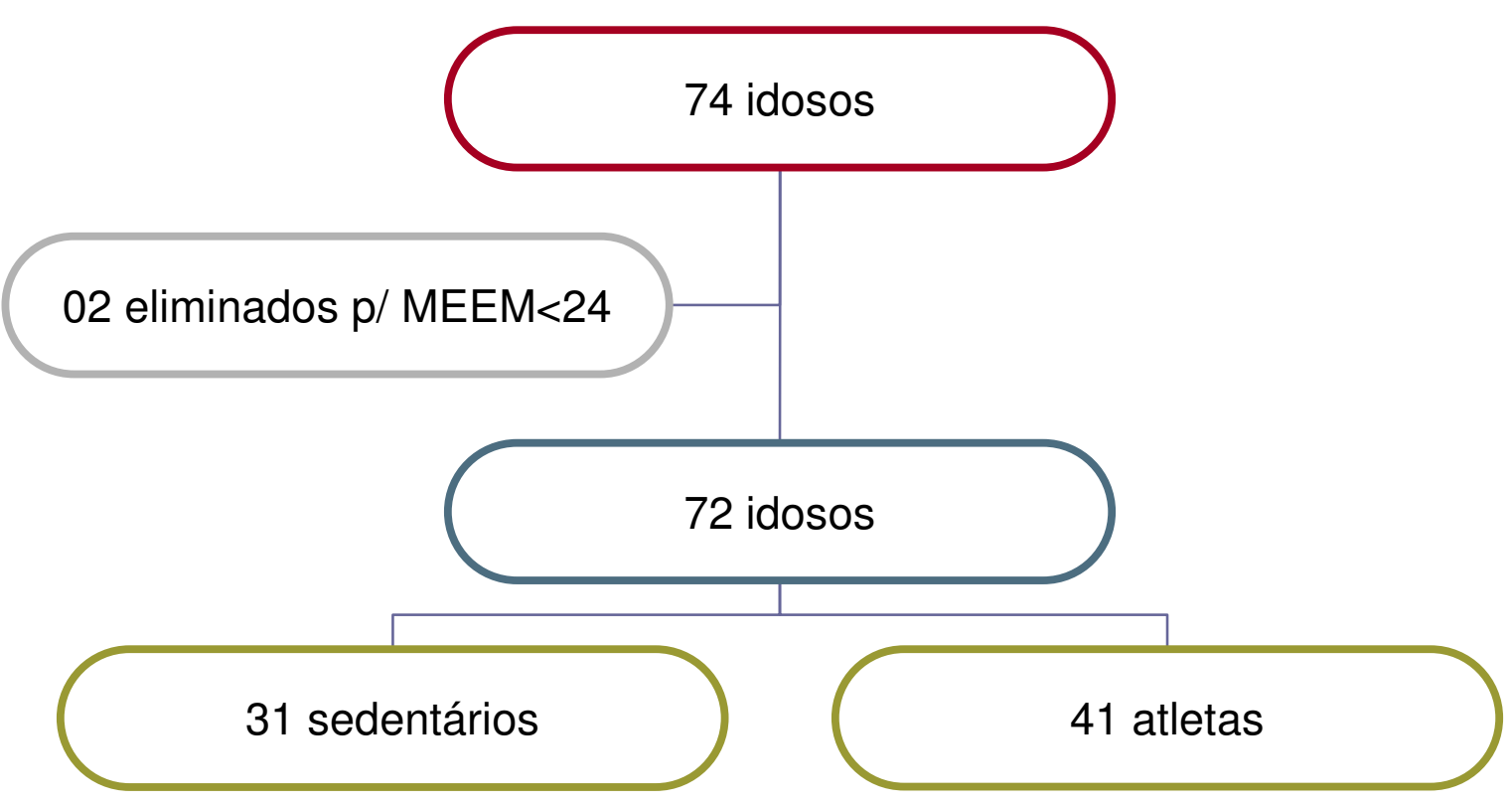




\section{Avaliação Laboratorial dos Biomarcadores}

Foram coletados amostras do sangue periférico de todos os participantes. No grupo dos atletas, a coleta foi realizada após um período de no mínimo 12 horas sem exercício, para evitar alterações agudas nos marcadores biológicos após treino físico. A coleta e análise laboratorial foram realizadas no Laboratório de Neurociências (LIM 27) do Instituto de Psiquiatria da Universidade de São Paulo. A seguir, um resumo da avaliação:

A atividade da GSK3 foi avaliada pelo método de ELISA, e demonstrada na pesquisa pela rGSK3, relação entre a GSK3 inativa e fosforilada ( PGSK3) e a GSK3 total (GSK3T), quanto maior a rGSK3 menor atividade da GSK3.

Análise laboratorial mais detalhada está no anexo 8.

\section{Avaliação Estatística}

Foi realizada a distribuição de freqüência, absoluta (n) e relativa (\%), dos dados enumerativos (atributos ou dados nominais) e a estatística descritiva dos dados quantitativos (grandezas específicas ou variáveis).

Para as comparações de variáveis categóricas entre as amostras, foi utilizado o teste de qui-quadrado ou, na impossibilidade de seu uso, o teste exato de Fisher.

Para as comparações entre as variáveis contínuas, foi utilizado o teste $t$ de student, no caso de distribuições paramétricas, ou o teste $U$ de Mann-Whitney, no caso de distribuições não paramétricas.

Os resultados foram apresentados em tabelas de contingência (atributos) ou estatísticas (grandezas). Foi utilizado o arredondamento científico. Foi adotado o nível de significância de $5 \%(\alpha=0,05)$. Foi utilizado o programa SPSS versão 14.0. 
Tomando como parâmetros uma chance de erro tipo 1 de $5 \%$ (alpha=0,05) e erro tipo 2 de 20\% (beta=0,20), calculamos que uma amostra de 72 participantes seria suficiente para detectar magnitudes de efeito de 0,7 na comparação de variáveis contínuas entre dois grupos.

\section{Resultado}

Houve semelhança entre as características clínicas e sociais dos idosos atletas e sedentários. A média de idade foi de 71,7 ( $\mathrm{DP}=5,2)$ anos entre os atletas e 72,8 anos $(\mathrm{DP}=5,3)$ entre os inativos, a média escolaridade em anos foi de 9,1 anos (DP= $5,5)$ e 8 anos ( $D P=5,1)$ nos sedentários. O estado civil também foi similar entre os grupos, $88,1 \%$ dos atletas e $85,3 \%$ dos sedentários estão casados. A atividade profissional também foi comparável entre os grupos, sendo que a maioria dos idosos está aposentada, havendo porém 42,9\% dos atletas e 32,4\% dos sedentários em atividade profissional. A escala de depressão geriátrica (EDG) foi semelhante entre os dois grupos, média de 1,93 pontos ( $D P=1,47)$ nos atletas e 2,12 ( $D P=1,65)$ nos sedentários, não apresentou nenhum idoso com depressão entre os dois grupos, já que a suspeita de transtorno do humor é feita com pontuação acima de cinco pontos. O Mini Exame do Estado Mental (MEEM) também mostrou desempenho cognitivo semelhante entre os grupos, uma média de 27,6 pontos ( $D P=2$ ) entre os atletas e 27,6 pontos $(\mathrm{DP}=1,9)$ entre os sedentários, afastando casos de demência, já que os idosos não apresentavam alteração funcional e exame cognitivo normal para seu grau de escolaridade, que também foi semelhante entre os grupos.

As comorbidades também foram semelhantes entre os grupos, $43,9 \%$ de hipertensos, $4,8 \%$ de diabéticos e $21,9 \%$ de dislipidêmicos entre os atletas e $54 \%$ de hipertensos, 9,6\% de diabéticos e 32,2\% de dislipidêmicos entre os sedentários. Não houve coronariopatas entre os atletas, dois idosos sedentários tinham história insuficiência coronariana estável, sem alteração de funcionalidade e assintomáticos. Nenhum idoso do estudo apresentava insuficiência cardíaca congestiva ou doença pulmonar obstrutiva crônica ou doença hepática. Um idoso atleta apresentava Insuficiencia renal crônica (Clearence de creatinina em torno de $50 \mathrm{ml} / \mathrm{min}$ ) e um idoso sedentário tinha história de acidente vascular encefálico isquêmico prévio, sem 
seqüelas motoras ou cognitivas. A média do número de medicações foi de 1,17 $(\mathrm{DP}=1,15)$ entre os atletas e 1,88 $(\mathrm{DP}=1,93)$ entre os sedentários. Não há tabagista nos dois grupos.

Apenas a renda salarial e o IMC foram diferentes entre os grupos. Os atletas apresentavam um renda mensal média de 8,6 $(\mathrm{DP}=5,9)$ salários mínimos, contra 5,8 $(\mathrm{DP}=5,0)$ entre os sedentários. Além disso, o Indice de Massa Corpórea (IMC, mensurado em $\mathrm{KG} / \mathrm{m}^{2}$ ) foi pouco maior no grupo sedentário 25,57 ( $\left.\mathrm{DP}=2,97\right)$, contra $23,85(\mathrm{DP}=2,29)$ nos atletas, entretanto apenas um idoso do grupo de atletas e dois idosos do grupo sedentário apresentava IMC maior que 30, todos abaixo de 32 $\mathrm{Kg} / \mathrm{m} 2$.

A Tabela 1 abaixo demonstra as características dos grupos e as análises estatísticas dos dados. 
Características de Atletas $(\mathrm{N}=41)$ e Sedentários $(\mathrm{N}=31)$

\begin{tabular}{|l|r|r|r|r|r|}
\hline \multirow{2}{*}{ Variável } & \multicolumn{2}{|c|}{ Atletas } & \multicolumn{2}{c|}{ Sedentários } & \multirow{2}{*}{${ }^{*} \mathrm{P}=$} \\
\cline { 2 - 5 } & média & \multicolumn{1}{c|}{ DP } & média & \multicolumn{1}{c|}{ DP } & \\
\hline Idade (anos) & 71,7 & 5,2 & 72,8 & 5,3 & 0,34 \\
Renda Familiar (SM) & 8,6 & 5,9 & 5,8 & 5 & 0,03 \\
Escolaridade (anos) & 9,1 & 5,5 & 8 & 5,1 & 0,36 \\
IMC & 23,85 & 2,29 & 25,57 & 2,97 & 0,01 \\
EDG & 1,93 & 1,47 & 2,12 & 1,65 & 0,59 \\
MEEM & 27,6 & 2 & 27,6 & 1,9 & 0,99 \\
№ Medicações & 1,17 & 1,15 & 1,88 & 1,93 & 0,06 \\
\hline Variável & $n$ & $\%$ & $n$ & $\%$ & $\mathrm{P}=$ \\
\hline Hipertensão Arterial & 18 & $43,90 \%$ & 17 & $54,84 \%$ & 0,34 \\
Diabetes Mellitus & 2 & $4,88 \%$ & 3 & $9,68 \%$ & 0,39 \\
ICO & 0 & $0,00 \%$ & 2 & $6,45 \%$ & 0,08 \\
AVC & 0 & $0,00 \%$ & 1 & $3,23 \%$ & 0,44 \\
DLP & 9 & $21,95 \%$ & 10 & $32,26 \%$ & 0,29 \\
Nefropatia & 1 & $2,44 \%$ & 0 & $0,00 \%$ & 0,55 \\
Ativo profissionalmente & 18 & $43,90 \%$ & 11 & $35,48 \%$ & 0,24 \\
Estado Civil & & & & & $0,98 * *$ \\
$\quad$ Solteiro & 1 & $2,44 \%$ & 1 & $3,23 \%$ & \\
Viúvo & 2 & $4,88 \%$ & 2 & $6,45 \%$ & \\
Casado & 36 & $87,80 \%$ & 26 & $83,87 \%$ & \\
Divorciado & 2 & $4,88 \%$ & 2 & $6,45 \%$ & \\
\hline
\end{tabular}

${ }^{*} \mathrm{P}$ - Teste de Fisher; ${ }^{* *}$ Teste do $X^{2}$

\section{Legenda:}

IMC= Indice de Massa Corpórea, $\mathrm{KG} / \mathrm{m} 2$

$E D G=$ Escala de Depressão Geriátrica

MEEM= Mini Exame do Estado Mental

$\mathrm{SM}=$ Salários Mínimos

$\mathrm{DLP}=$ Dislipidemia, $\mathrm{ICO}=$ Insuficiencia coronariana, $\mathrm{AVC}=$ Acidente Vascular cerebral

O nível de atividade física foi diferente entre os grupos: os atletas foram classificados pelo IPAQ como muito ativos (31) e ativos (10), no grupo sedentários, 08 como sedentários e 23 como insuficientemente ativos. A média de atividade física moderada ou vigorosa aeróbica no grupo de atletas foi 318,1 minutos/semana ( $D P=181,3)$ e de atividade física moderada ou vigorosa resistida foi de 98,2 minutos por semana $(\mathrm{DP}=96)$. No grupo sedentários a média de atividade física aeróbica leve, caminhada, foi de 61,1 minutos por semana ( $D P=70,7)$, nenhum idoso praticava atividade física resistida no grupo de inativos. 
Tabela 2 abaixo demonstra nível de atividade física entre grupos:

Características dos 41 Atletas e dos 31 Sedentários

\begin{tabular}{|c|c|c|c|c|c|}
\hline \multirow[b]{2}{*}{ Variável } & \multicolumn{2}{|c|}{ Atletas } & \multicolumn{2}{|c|}{ Sedentários } & \multirow[b]{2}{*}{$P=$} \\
\hline & $\begin{array}{c}\text { média (em } \\
\text { min) }\end{array}$ & DP & $\begin{array}{c}\text { média (em } \\
\text { min) }\end{array}$ & DP & \\
\hline Ativ. Física Aeróbica /Semana & 318,1 & 181,3 & 61,1 & 70,7 & $<0,001$ \\
\hline Ativ. Física Resistida /Semana & 98,2 & 96 & 0 & 0 & - \\
\hline Ativ. Física Total /Semana & 416,8 & 190,8 & 60,5 & 71,2 & $<0,001$ \\
\hline
\end{tabular}

\section{Gráfico 1 - Atividade da GSK entre atletas e sedentários}

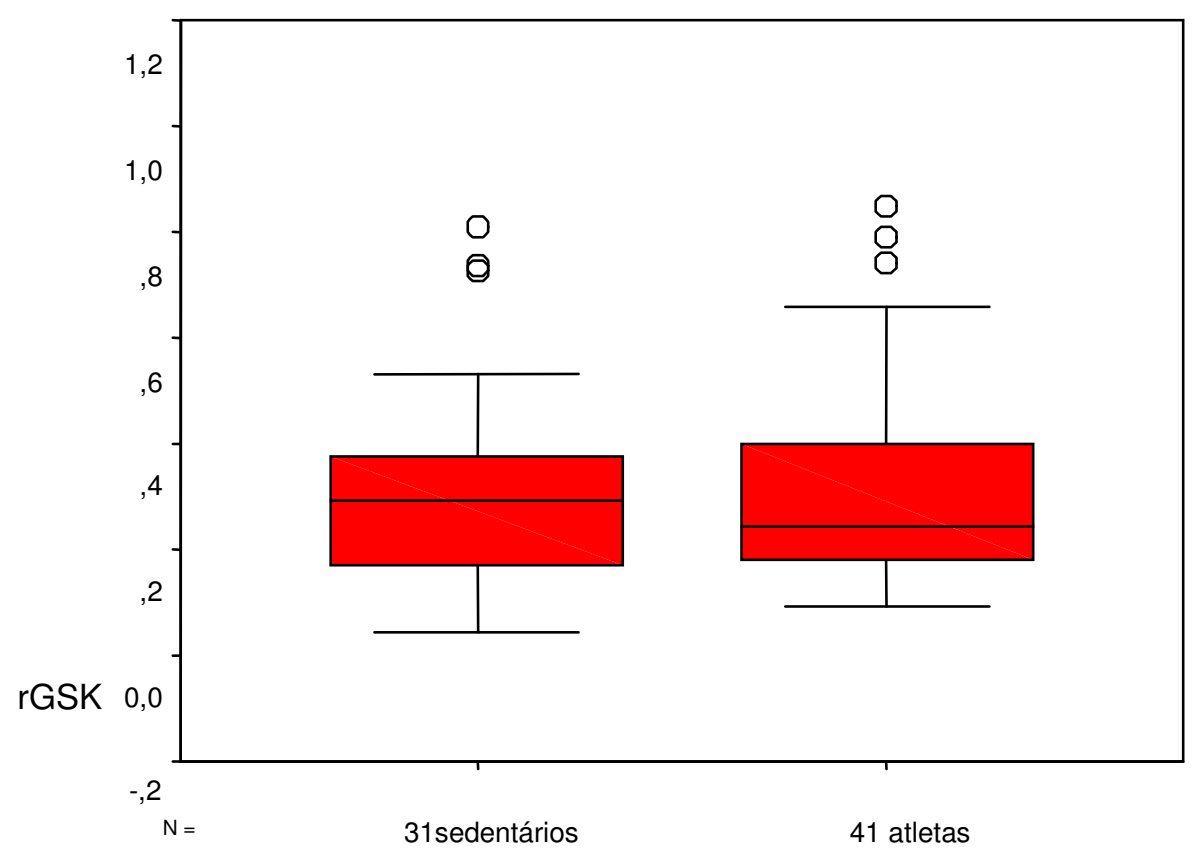


Gráfico 2 - Atividade da GSK3 relacionado ao nível de atividade física pelo IPAQ

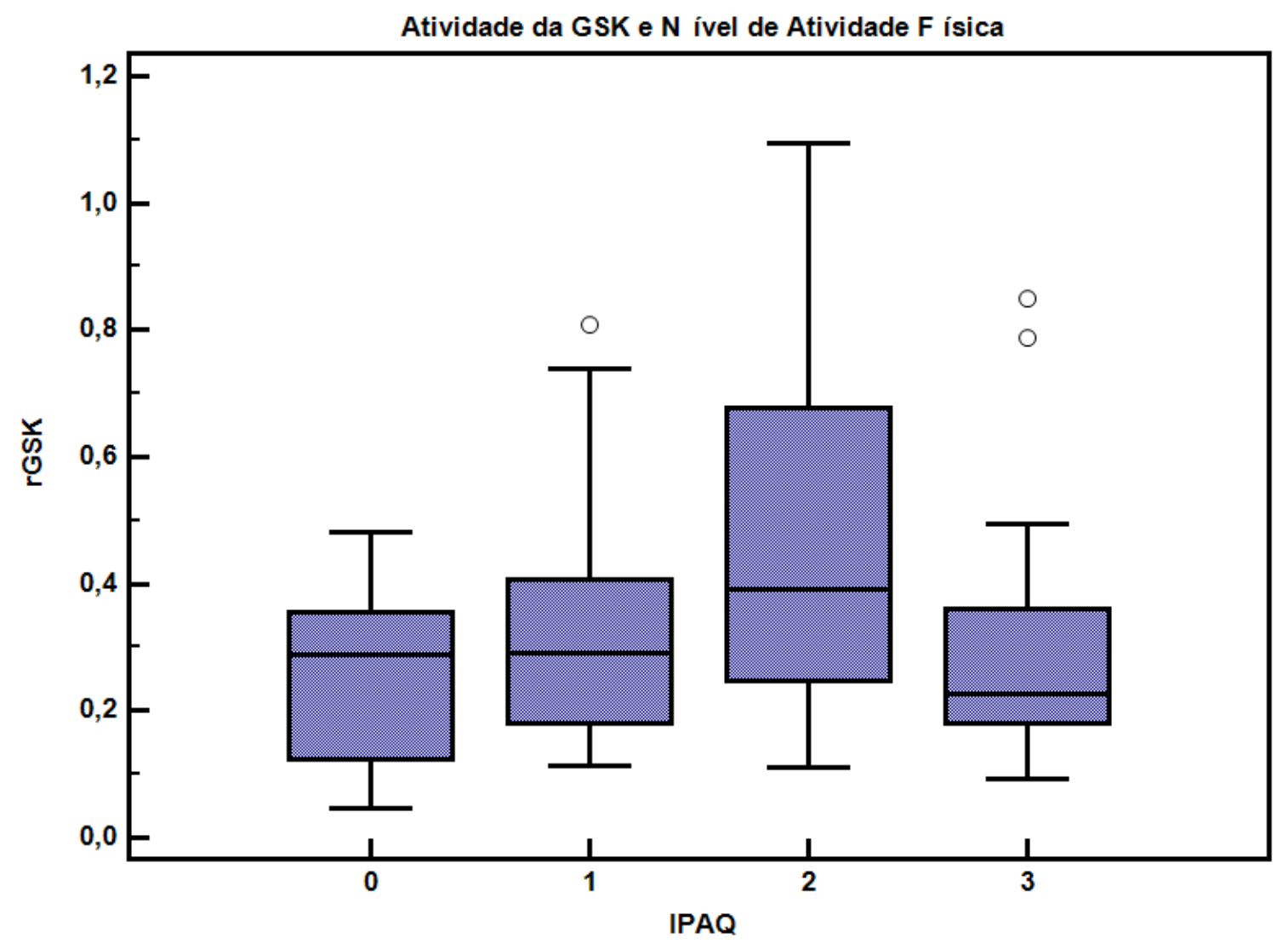

A atividade da GSK3ß foi medida pela r-GSK (relação entre GSK fosforilada e inativa sobre GSK total), quanto maior a rGSK3, maior inativação da enzima e melhores efeitos sobre a cognição. Não houve diferença estatística na atividade da GSK3 entre os grupos de atletas e sedentários quando separado em dois grupos (sedentários e atletas). Quando dividido os níveis de atividade física pelo IPAQ (sedentário $=0$, insuficientemente ativo $=1$, ativo $=2$ e muito ativo $=3$ ) ocorreu uma tendência de maior inativação da GSK3 no grupo de idosos ativos, porém a atividade da GSK3 foi muito semelhante entre os muito ativos e os sedentário. Apesar das variações no gráfico 2, também não houve diferença estatística entre os quatro grupos. 


\section{Discussão}

Nossos resultados não conseguiram demonstrar associação entre nível de atividade física em idosos e a atividade da GSK3, houve uma tendência a redução da atividade de GSK entre os atletas(ativos) sem significância estatística.

Os dois grupos foram semelhantes para variáveis clínicas e sociais, apenas o IMC foi maior entre os sedentários, mas houve um número muito pequeno de obesos (IMC entre $30-35 \mathrm{KG} / \mathrm{m} 2$ ), 03 pacientes, dois no grupo sedentário e um no grupo de atletas. Além disso, a renda salarial foi maior no grupo de atletas, todas as outras variáveis foram semelhantes entre os grupos. Os estudos sobre nível econômico e atividade física não são homogêneos, um estudo entre adultos usuários do sistema de saúde público e privado, em São Paulo, mostrou maior nível de atividade física entre indivíduos conveniados e com melhor renda salarial. ${ }^{105}$ Outro estudo com idosas, em Santa Catarina, não mostrou interferência da classe econômica sobre o nível de AF, porém ocorreu uma tendência a inatividade na classe $E^{106}$. Este estudo também mostrou menor renda salarial entre os mais sedentários.

Nosso estudo possui uma amostra de idosos homens e com boa funcionalidade, não podendo ser generalizada para outras populações. Além disso, os pacientes são oriundos de ambulatórios relacionados à promoção de saúde, onde são sempre estimulados a atividade física. Apenas oito pacientes no grupo não-atletas eram completamente sedentários pelo IPAQ. Apesar disso, a diferença entre o tempo gasto com atividade física por semana foi muito diferente entre os grupos, 416 minutos entre os atletas e 60 minutos entres os sedentários.

Há uma dificuldade em encontrar idosos completamente sedentários e com boa funcionalidade. Nossos dois grupos são formados por idosos muito saudáveis, apesar da diferença de atividade física. Talvez o nível de atividade física com movimentos do cotidiano nos idosos sedentários saudáveis seja suficiente para modular os biomarcadores de neuroproteção.

Estudo recente, já citado anteriormente ${ }^{37}$, mostrou que o gasto energético total, avaliado pela técnica da água duplamente marcada teve melhor correlação com déficit cognitivo do que avaliações de atividade física por entrevista. O grupo de 
sedentários pode ter uma vida ativa, porém sem atividade física regular, e este trabalho mostra que o gasto energético é um fator mais importante para melhora cognitiva. A maioria dos questionários de avaliação de atividade física foca nas atividades moderadas e vigorosas, mas não estão adequados para atividades de baixa intensidade, como alocação postural, mexer-se, movimentos ao redor da casa, etc. Estas atividades não são detectadas pelo IPAQ e são responsáveis pela maioria do gasto energético entre indivíduos sedentários, deste modo o gasto enérgico estaria subestimado entre os sedentários. Outro estudo mostrou correlação positiva entre os movimentos do dia-a-dia de mulheres idosas e o desempenho cognitivo ${ }^{107}$, reforçando a idéia que o gasto energético com atividades de baixa intensidade tem efeito positivo sobre a neuroproteção.

O IPAQ é um dos questionários mais utilizados para avaliar o nível de atividade física, usado em várias faixas etárias, padronizado pela OMS (Organização Mundial da Saúde), com objetivo de homogeneizar as informações. A versão curta foi validada no Brasil $^{102}$ em 2001, o método de referência utilizado foi um sensor de movimento, os coeficientes de correlação foram baixos a moderados $(r=0,75$ para forma curta), embora similares a outros instrumentos. O valor de atividade física referido nos questionários é normalmente superestimado, por ser uma prática saudável e bem vista socialmente. Um estudo em indivíduos voluntários no InCor (Instituto do Coração do Hospital das Clínicas da FMUSP) observou que o questionário IPAQ superestimou como ativa cerca de $50 \%$ da população, quando comparado ao teste ergométrico.

É possível que a amostra tenha sido insuficiente para demonstrar a influencia da atividade física sobre a GSK3; não existem estudos em humanos avaliando esta associação. Um estudo em humanos que avalia a atividade de GSK3 no sangue periférico de pacientes com DA, transtorno cognitivo leve e controle, mostrando diferença significativa entre os grupos, a amostra do estudo é de 113 pacientes $^{71}$.

A atividade física pode ter uma maior influência sobre o aumento no nível dos agentes anti-inflamatórios e anti-oxidantes ${ }^{108}$, e não influenciar diretamente a GSK3, porém apenas um trabalho controlado, avaliando o nível da GSK3 num grupo de 
pacientes antes e após um programa de exercício pode confirmar definitivamente a associação entre exercício e atividade da GSK3.

Apesar do efeito sobre as mesmas citocinas (IL-1 e TNF) moduladas pela GSK3, o exercício pode atuar através de outra via reduzindo a produção de citocinas e ativando complexos protéicos (proteosoma) responsáveis degradação das proteínas danificadas e pelo reparo no DNA danificado pela inflamação. Além disso, o mecanismo pelo qual a atividade física influencia a cognição pode ser multifatorial, melhorando a neuroplasticidade pelo aumento de neurotrofinas ( BDNF), reduzindo os riscos cardiovasculares com HAS, diabetes e obesidade.

\section{Conclusão}

Nosso estudo não conseguiu demonstrar associação entre atividade física e os níveis da GSK3 no sangue periférico. A amostra de idosos muito saudáveis e a provável influência de atividades de baixa intensidade sobre o desempenho cognitivo enfraqueceram o poder do estudo. Será necessário um estudo com número maior de pacientes, que utilize métodos mais precisos de aferição de atividade física, que não foque apenas atividades moderadas e vigorosas. Outra alternativa é que a ação protetora do exercício não utilize esta via enzimática(GSK3). 


\section{Referências}

1 IBGE, Diretoria de Pesquisas. Coordenação de População e Indicadores Sociais. Gerência de Estuidos e Análises de Dinâmicas Demográficas. Projeção da População do Brasil por sexo e idade: 1980-2050 - Revisão 2010.

2 Hazzard W, Blass J, Halter J, Ouslander J, Tinetti M. Principles of Geriatric Medicine \& Gerontology. McGraw-Hill Companies, 2003.

3 Freitas EV, Py L, Cançado FAX, Doll J, Gorzoni Ml. Tratado de Geriatria e Gerontologia. $2^{\mathrm{a}}$ edição , Rio de Janeiro: Guanabara Koogan, 2006.

4 Hebert LE, Scherr PA, Bienias JL. Alzheimer's disease in the US population: prevalence estimates using the 2000 census. Arch Neurol. 2003;60(8):1119-1122.

5 Herrera JrE, Caramelli P, Silveira ASB, Nitrini R. Epidemiologic survey of dementia in a comunitydwelling Brazilian population. Alzheimer Dis Assoc Disord, 2002;16(2):10-108.

6 Bottino CMC, Lopes MA, Moreno MPQ. Prevalência de demência em ma amostra comunitária de São Paulo. Arq Neuropsiquiatr, 2004;63(suppl 2):32.

7 Montaño MB, Loening A, Ramos L, et al. Prevalência de demência em uma coorte de idosos de comunidade. Arq Neuropsiquitr, 2001; 59( suppl 3):2.

8 Berlin JA, Colditz GA. A meta-analysis of physical activity in the prevention of coronary heart disease. Am J Epidemiol. 1990;132(4):612-628.

9 Albright A, Franz M, Hornsby G. American College of Sports Medicine position stand: exercise and type 2 diabetes. Med Sci Sports Exerc. 2000;32(7): 1345-1360

10 Warburton DE, Nicol CW, Bredin SS. Health benefits of physical activity: the evidence. CMAJ. 2006;174(6):801-809.

11 Layne JE, Nelson ME. The effects of progressive resistance training on bone density: a review. Med Sci Sports Exerc 1999; 31:25-30.

12 Yaffe K, Barnes D, Nevitt M, Lui LY, Covinsky K. A prospective study of physical activity and cognitive decline in elderly women: women who walk. Arch Intern Med 2001;161:1703-1708.

13 Barnes DE, Yaffe K, Satariano WA, Tager IB. A longitudinal study of cardiorespiratory fitness and cognitive function in healthy older adults. J Am Geriatr Soc 2003; 51:459-465. 
14 Abbot RD, White LR, Ross GW. Walking and dementia in physically capable elderly men. JAMA $2004 ; 292: 1447-1453$.

15 Weuve J, Kang JH, Manson JE, et al. Physical activity, including walking, and cognitive function in older women. JAMA 2004; 292:1454-1461.

16 Larson EB, Wang L, Bowen JD, et al. Exercise is associated with reduced risk for incident dementia among persons 65 years of age and older. Ann Intern Med 2006; 144:73.

17 Yates L B, Djousse ' L, Kurth T, Buring JE, Gaziano JM. Exceptional Longevity in Men. Arch Intern Med. 2008;168(3):284-290.

18 Radak Z, Chung HY, Goto S. Exercise and hormesis: oxidative stress-related adaptation for successful aging. Biogerontology. 2005;6(1):71-75.

19 Finkel T, Holbrook NJ. Oxidants, oxidative stress and the biology of ageing. Nature. 2000;408(6809):239-247.

20 Finch CE, Crimmins EM. Inflammatory exposure and historical changes in human life-spans. Science. 2004;305(5691):1736-1739.

21 Chen JH, Lin KP, and Chen YC. Risk factors for dementia. J Formos Med Assoc. 2009;108:754-64.

22 Pope SK, Shue VM and Beck C. Will a healthy lifestyle help prevent Alzheimer's disease? Annu Rev Publ Health. 2003: 24: 111-132.

${ }^{23}$ Diniz BSO, Pinto J J A, Forlenza, O V . Do CSF total tau, phosphorylated tau, and $\beta$-amyloid 42 help to predict progression of mild cognitive impairment to Alzheimer's disease? Asystematic review and meta-analysis of the literature', World Journal of Biological Psychiatry. 2007;10:1-11.

24 Chan KL, Tong KY, Yip SP. Relationship of serum brain-derived neurotrophic factor (BDNF) and health-related lifestyle in healthy human subjects . Neuroscience Letters. 2008; 447:124-128.

25 Tang SW, Chu E, Hui T, Helmeste D, Law C. Influence of exercise on serum brain-derived neurotrophic factor concentrations in healthy human subjects . Neuroscience Letters. 2008; 431:6265.

26 Cooper DM, Aizik SR, Zaldivar F, Leu SY, Galasseti P. Effects of 30 min of aerobic exercise on gene expression. J Appl Physiol. 2008;104:236-243. 
27 Cases N, Aguilo A, Tauler P, Sureda A, Pons A, Tur JÁ, Roche E, Cordova A, Maestre I. Response of antioxidant defences to oxidative stress induced by prolonged exercise: antioxidant enzyme gene expression in lymphocytes. Eur J Appl Physiol. 2006;98:263-269.

28 Lambert CP, Wright NR, Finck BN, Villareal DT. Exercise but not diet-induced weight loss decreases skeletal muscle inflammatory gene expression in frail obese elderly persons. J Appl Physiol. 2008;105(2):473-8.

29 Bean JF, Vora A, Frontera WR. Benefits of exercise for community-dwelling older adults. Arch Phys Med Rehabil. 2004;85(3 Supl ):S31-42.

30 Qiang MA. Beneficial effects of moderate voluntary physical exercise and its biological mechanisms on brain health. Neurosci Bull. 2008; 24(4): 265-270.

31 Abbott RD, White LR, Ross GW. Walking and dementia in elderly men. JAMA. 2004;292(12):14471453.

32 Yaffe K, Barnes D, Nevitt M. A prospective study of physical activity and cognitive decline in elderly women: women who walk. Arch Intern Med. 2001;161:1703-1707.

33 Barnes DE, Yaffe K, Satariano WA, Tager IB. A longitudinal study of cardiorespiratory fitness and cognitive function in healthy older adults. J Am Geriatr Soc 2003; 51:459-465.

34 Larson EB, Wang L, Bowen JD, e cols. Exercise is associated with reduced risk for incident dementia among persons 65 years of age and older. Ann Intern Med 2006; 144:73.

35 Scarmeas N; Luchsinger JA; Schupf N; e cols. Physical activity,diet, and risk of Alzheimer disease. JAMA 2009; 302:627-637.

36 Lautenschlager NT, Cox KL, Flicker L. Effect of physical activity on cognitive function in older adults at risk for alzheimer disease. JAMA 2008;300:1027-1037.

37 Middleton LE, Manini TM, Simonsick EM. Activity energy expenditure and incident cognitive impairment in older adults. Arch Intern Med. 2011;171(14):1251-1257.

38 Chakravarty EF, Hubert HB, Lingala VB, Fries JF. Reduced Disability and Mortality among Aging Runners: a 21-year Longitudinal Study. Arch Intern Med. 2008; 168(15): 1638-1646.

39 Lee M, Paffenbarger RS. Associations of Light, Moderate, and Vigorous Intensity Physical Activity with Longevity. Am J Epidemiol.2000;151-3: 293-99. 
40 Van Praag H. Neurogenesis an exercise: past end future directions. Neuromol Med. 2008;10:128140.

41 Kuhn HG, Dickinson-Anson H, Gage FH. Neurogenesis in the dentate gyrus of the adult rat: agerelated decrease of neuronal progenitor proliferation. Journal of Neuroscience. 1996;16:2027-2033.

42 Van Praag H, Schinder AF, Christie BR, Toni N, Palmer TD, Gage FH. Funcional neurogenesis in the adult hippocampus. Nature. 2002;415:1030-1034.

43 Van Praag H. Neurogenesis and exercise: past and futures directions. Neuromol Med 2008;10:128140.

44 Fabel K, Kempermann G. Physical activity end the regulation of neurogenesis in the adult and aging brain. Neuromol Med. 2008;10:59-66.

45 Kronenberg G, Bick-Sander A, Bunk E. Physical exercise prevents age-related decline in precursor cell activity in the mouse dentate gyrus. Neurobiology of Aging.2006;27:1505-1513.

46. Seki T, Arai Y. Age-related production of a new granule cells in the adult dentate gyrus. Neuroreport.1995;6:2479:2482.

47 Cameron HA, Mckay RD. Restoring production of hippocampal neurons in old age. Nature Neuroscience. 1999;2:894-897.

48 Van Praag H, Shubert AF, Zhao C, Gage FH. Exercise enhances learning and hippocampal neurogenesis in aged mice. Journal of Neuroscience. 2005;25:8680-8685.

49 Stranahan AM, Khalil D, Gould E. Running induces widespread structural alterations in the hippocampus and entorhinal cortex. Hippocampus. 2007;17:1017-1022.

50 Redila VA, Christie BR. Exercise-induced changes in dendritic structure and complexity in the adult hippocampal dentate gyrus. Neuroscience. 2006;137:1299-1307.

51 Bliss TV, Collingridge GL. A synaptic model of memory: long-term potentiation in the hippocampus. Nature.1993,361:31-39.

52 Molteni R, Ying Z, Gómez-Penilha F. Differential effects of acute and chronic exercise on plasticityralated genes in the rat hippocampus revealed by microarray. European Journal of Neuroscience. 2002;16:1107-1116. 
$53 \mathrm{Ge}$ S, Yang $\mathrm{CH}$, Hsu KS, Ming GL, Song H. A critical period for enhanced synaptic plasticity in newly generated neurons in the adult brain. Neuron. 2007;54(4):559-566.

54 Farmer J, Zhao X, van Praag H, Wodtke K, Gage FH, Christie BR. Effects of voluntary exercise on synaptic plasticity and gene expression in the dentate gyrus of adult male Sprague-dawley rats in vivo. Neuroscience. 2004;124:71-79.

55 Babyak M, Blumenthal JA, Herman S, Khatri $\mathrm{P}$ e cols. Exercise treatment for major depression: maintenance of therapeutic benefit at 10 months. Psychosomatic Medicine. 2000;63:633-638.

56 Jacobs BL, van Praag H, Gage FH. Adult brain neurogenesis and psychiatry: a novel theory of depression. Molecular Psychiatry 2000;5:262-269.

57 Calof AL. Intrinsic and extrinsic factors regulating vertebrate neurogenesis. Current opnion in neurobiology.1995;5:19-27.

58 Pereira Ac, Huddleston DE, Brickman AM e cols. An in vivo correlate of exercise -induced neurogenesis in the adult dentate gyrus. Proceedings of the National Academy of Sciences of the United States of America 2007;104:5638:5643.

59 Packer N, Pervaiz N, Hoffman-Goetz L. Does exercise protect from cognitive decline by altering brain cytokine and apoptotic protein levels? A systematic review of the literature. Exerc Immunol Rev. 2010;16:138-62.

60 Radak Z, Chung HY, Goto S. Exercise and hormesis: oxidative stress-related adaptation for successful aging. Biogerontology. 2005;6(1):71-5.

61 Jope RS, Yuskaitis CJ, Beurel E. Glycogen Synthase Kinase-3 (GSK3): Inflammation, Diseases, and Therapeutics. Neurochem Res. 2007; 32:577-595

62 Jope RS, Johnson GVW . The glamour and gloom of glycogen synthase kinase-3 (GSK3). Trends Biochem Sci. 2004;29:95-102

63 Martin M, Rehani K, Jope RS, Michalek SM. Tolllike receptor-mediated cytokine production is differentially regulated by glycogen synthase kinase 3. Nat Immunol. 2005;6:777-784

64 Imitola J, Chitnis T, Khoury SJ . Insights into the molecular pathogenesis of progression in multiple sclerosis: potential implications for future therapies. Arch Neurol. 2006; 63:25-33.

65 Kielian T. Toll-like receptors in central nervous system glial inflammation and homeostasis. J Neurosci Res. 2006; 83:711-730. 
66 Hernandez F., Borrell J., Guaza C., Avila J. and Lucas J. J. Spatial learning deficit in transgenic mice that conditionally over-express GSK-3 beta in the brain but do not form tau filaments. J. Neurochem.2002; 83, 1529-1533.

67 Engel T., Goni-Oliver P., Lucas J. J., Avila J. and Hernandez F. Chronic lithium administration to FTDP-17 tau and GSK-3beta overexpressing mice prevents tau hyperphosphorylation and neurofibrillary tangle formation, but pre-formed neurofibrillary tangles do not revert. J. Neurochem. 2006; 99:1445-1455.

68 Teter B., Morihara T., Lim G. P., Ambegaokar S. S., Ubeda O. J., Frautschy S. A. and Cole G. M. Insulin-degrading enzyme as a downstream target of insulin receptor signaling cascade: implications for Alzheimer's disease intervention. J. Neurosci.2004; 24:11120-11126.

69 Reger M. A., Watson G. S., Green P. S. Intranasal insulin improves cognition and modulates \{beta\}-amyloid in early AD. Neurology 2008;70:1-10.

${ }^{70} 70$ Rodionova E., Conzelmann M., Maraskovsky E., Hess M., Kirsch M., Giese T., Ho A. D., Zoller M., Dreger P. and Luft T. GSK-3 mediates differentiation and activation of proinflammatory dendritic cells. Blood. 2007;109:1584-1592.

71 Hye A, Kerr F, Archer N, Foy C, Poppe M, Brown R, Hamilton G, Powell J, Anderton B, Lovestone $S$. Glycogen synthase kinase-3 is increasing in white cells early in Alzheimer's disease. Neuroscience Letters. 2005; 373:1-4.

72 Amaducci LA, Rocca WA, Schoenberg BS. Origin of the distinction between Alzheimer's disease and senile dementia: how history can clarify nosology. Neurology.1986;36:1497-9.

73 Boller F, Forbes MM. History of dementia and dementia in history:an overview. J Neurol Sci. 1998;158:125-33.

74 Katzman R. The prevalence and malignancy of Alzheimer's disease:a major killer. Arch Neurol. 1976;33:217-8.

75 Ravaglia G, Forti P, Maioli F, Martelli M, Servadei L, Brunetti N,et al. Incidence and etiology of dementia in a large elderly Italian population. Neurology.2005;64:1525-30.

76 Jorm AF, Jolley D. The incidence of dementia: a meta-analysis. Neurology.1998;51:728-33.

77 Freitas E.V, Py L, Gorzoni M. Tratado de Geriatria e Gerontologia. 2 ${ }^{\mathrm{a}}$ ed. Rio de Janeiro: Guanabara Koogan. 2006. p. 225-237. 
78 Swerdlow R.H. Is aging part of Alzheimer's disease, or is Alzheimer's disease part of aging? Neurobiology of Aging. 2007;28:1465-1480.

79 Cummings JL, Cole G. Alzheimer disease. JAMA. 2002;287:2335-8.

80 Davis DG, Schmitt FA, Wekstein DR, Markesbery WR. Alzheimer neuropathologic alterations in aged cognitively normal subjects. J Neuropathol Exp Neurol.1999;58:376-88

81 Laferla FM, Green KN, Oddo S. Intracellular amyloid- $\beta$ in alzheimer's disease. Nature Reviews/Neuroscience. 2007;8:499-509.

82 Passer B, Pellegrini L, Russo C, Siegel RM, Lenardo MJ, Schettini G, et al. Generation of an apoptotic intracellular peptide by gamma secretase cleavage of Alzheimer's amyloid beta protein precursor. JAlzheimer Dis. 2000;2:289-301.

83 Vassar, R. $\beta$-secretase cleavage of Alzheimer's amyloid precursor protein by the transmembrane aspartic protease BACE. Science. 1999; 286:735-741.

$84 \mathrm{LaFerla} \mathrm{FM,} \mathrm{Green} \mathrm{KN,} \mathrm{Oddo} \mathrm{S.} \mathrm{Intracellular} \mathrm{amyloid-} \beta$ in Alzheimer's disease. Nature Reviews/ Neuroscience. 2007; $8:$ 499-507.

85 Jicha GA, Parisi JE, Dickson DW, Boeve BF, Knopman DS, Petersen RC. Alzheimer and Lewy body pathology in centenarian case series. Neurology 2005;6(Suppl. 1):A275

86 Polvikoski T, Sulkava R, Rastas S, Sutela A, Niinisto L, Notkola IL, et al. Incidence of dementia in very elderly individuals: A Clinical, Neuropathological and Molecular Genetic Study. Neuroepidemiology 2005;26:76-82.

87 Yaffe K, Weston A, Graff-Radford e cols. Association of Plasma $\beta$-Amyloid Level and Cognitive Reserve With Subsequent Cognitive Decline. JAMA. 2011; 305: 261-266.

88 Hartigan JA, Johnson GVW. Tau protein in normal and Alzheimer's disease brain: an update. Alzheimer Dis Rev. 1998;3:125-41.

89 Gong CX, Lidsky T, Wegiel J, Zuck L, Grundke-lqbal I, Iqbal K. Phosphorylation of microtubuleassociated protein tau is regulated by protein phosphatase $2 \mathrm{~A}$ in mammalian brain. Implications for neurofibrillary degeneration in Alzheimer's disease. J Biol Chem. 2000;275:5535-44.

90 Swerdlow R.H. Is aging part of Alzheimer's disease, or is Alzheimer's disease part of aging? Neurobiology of Aging. 2007; 28:1465-1480. 
91 Ballatore C, Lee VMY, Trojanowski JQ. Tau-mediated neurodegeneration in Alzheimer's disease and related disorders. Nature reviews/Neuroscience. 2007; 8: 663-672

92 Arriagada PV, Growdon, JH, Hedley-Whyte ET, Hyman BT. Neurofibrillary tangles but not senile plaques parallel duration and severity of Alzheimer's disease. Neurology. 1992;4:631-639.

93 Maeda S, et al. Increased levels of granular tau oligomers: an early sign of brain aging and Alzheimer's disease. Neurosci. Res.2006; 54:197-201.

94 Ballatore C, Lee VMY, Trojanowski JQ. Tau-mediated neurodegeneration in Alzheimer's disease and related disorders. Nature reviews/Neuroscience 2007; 8: 663-672.

95 Braak H, Braak E. Staging of Alzheimer's disease-related neurofibrillary changes. Neurobiol Aging. 1995;16:271-8.

96 Hof PR, Glannakopoulos P, Bouras C. The neuropathological changes associated with normal brain aging. Histol Histopathol.1996;11:1075-88.

97 Sato $Y$, Nanri H, Ohta M, Kasai H, Ikeda M. Increase of human MTH1 and decrease of 8hydroxydeoxyguanosine in leukocyte DNA by acute and chronic exercise in healthy male subjects. Biochem Biophys Res Commun. 2003;305: 333-33.

98 Cannon JG, Meydani SN, Fielding RA, Fiatarone MA, Meydani M, Farhangmehr M, Orencole SF; Blumberg JB, Evans WJ. Acute phase response in exercise. II. Associations between vitamin E, cytokines, and muscle proteolysis. Am J Physiol.2001;260:1235-1240.

99 Brucki SMD et al. Sugestões para o uso do Mini-Exame do Estado Mental no Brasil. Arq Neuropsiquiatr. 2003; 61(3-B): 777-781.

100 Fountoulakis KN, Tsolaki M, lacovides A, Yesavage J, O'Hara R, Kazis A. The validation of the short form of the geriatric depression scale (GDS) in Greece. Aging (Milano).1999;11(6):367-72.

101 Almeida OP, Almeida SA. Confiabilidade da versão brasileira da escala de depressão em geriatria (GDS) versão reduzida. Arq Neuropsiquiatr.1999;57(2B):421-6.

102 Matsudo SM, Araújo TL, Matsudo VKR, Andrade DR, Andrade EL, Oliveira LC. Questionário Internacional de Atividade Física (IPAQ): estudo de validade e reprodutibilidade no Brasil. Rev Bras Ativ Saude. 2001;10:5-18.

103 Katz S, Downs TV, Cash J, Grotz RC. Progress in the development of an índex of ADL. Gerontologist. 1970;10:20-30. 
104 Fillenbaum G. J Am Geriatr Soc 1985; 33:698-706.

105 Martinez AP, Martinez JE, Lanza LB. Há correlação entre classe social e a prática de atividade física? Acta Fisiatr. 2011; 18(1): $27-31$.

106 G Z Mazo, J Mota, LHT Gonçalves, MG Matos. Nível de atividade física, condições de saúde e características sócio-demográficas de mulheres idosas brasileiras. Rev Port Cien Desp. 2003;2(V) 202-212.

107 Barnes DE, Blackwell T, Stone KL, Goldman SE, Hillier T, Yaffe K; Study of Osteoporotic Fractures. Cognition in older women: the importance of daytime movement. J Am Geriatr Soc. 2008;56(9):1658-1664

108 Radak Z, Chung HY, Goto S. Exercise and hormesis: oxidative stress-related adaptation for successful aging. Biogerontology 2005; 6: 71-75.

\section{Apêndices}

\section{Anexo 1}

Atividades de Vida Diária

- Tomar banho

- Vestir-se

- Fazer o toalete

- Transferência de local

- Continência dos esfíncteres

- Alimentar-se sozinho

Katz. S et al. JAMA 1963; 185: 914-9 
Anexo 2

Atividades Instrumentais de Vida Diária

- Usar o telefone

- Deslocar-se (táxi, ônibus, automóvel)

- Fazer compras

- Preparar refeições

- Fazer os trabalhos de casa

- Administrar as próprias medicações

- Gerenciar o dinheiro

Fillenbaum G. J Am Geriatr Soc 1985; 33: 698-706 


\section{Anexo 3}

PROTOCOLO DE AVALIAÇÃO

Data da Coleta:

ATIVIDADE FÍSICA EM IDOSOS: EFEITO NOS BIOMARCADORES PERIFÉRICOS

DE NEUROPROTEÇÃO.

1. Identificaçăo

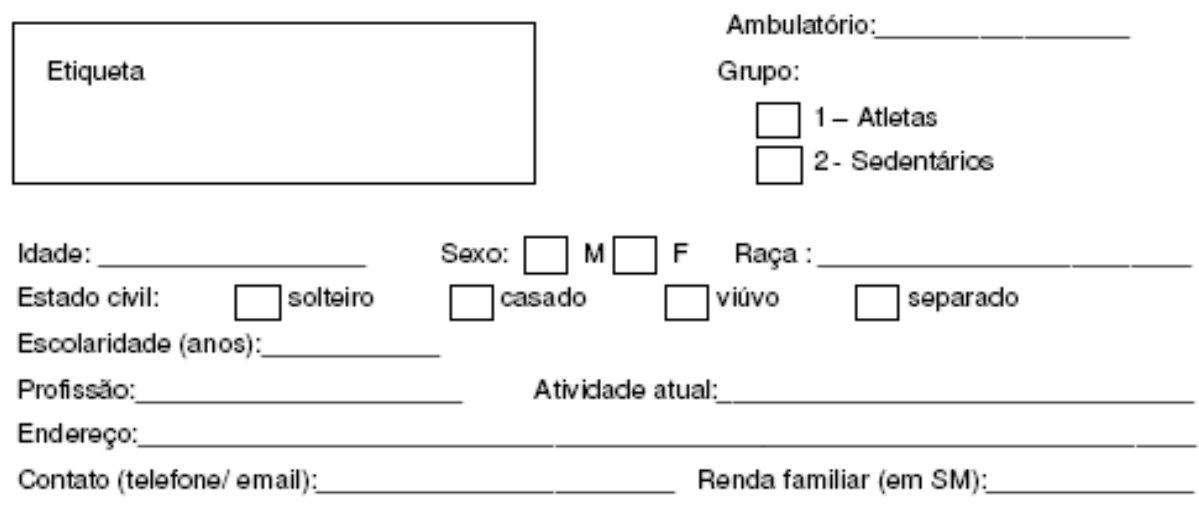

2. Auto-avaliaçăo do bem estar e saúde
$\square$ Ootimo
$\square$ Bom
Regular
Ruim
EDG (15) :

3. IPAQ (Versão Curta) $\square$ Muito Ativo $\square$ Ativo $\square$ Insuficientemente Ativo $\square$ Sedentário

4. Nivel de atividade física (mets)
$\square<4$ mets
$\square$ 4.7 mets
$\square>7$ mets

Freqũência e duraçăo da atividade física semanal (em minutos):

Ativ. fisica aeróbica: / semana minutos/semana.

Ativ. fisica resistida: /semana minutos/semana.

Total (min/sem):

Há quanto tempo:

5. Comorbidades

$\begin{array}{ll}\square \text { HAS } & \square \text { DM } \\ \square \text { ICO } & \square \text { AVC } \\ \square \text { Hepatopeatias } & \square \text { DLP }\end{array}$

$\square$ DPOC/Asma
$\square$ ICC
$\square$ Outros:

6. Medicamentos em uso:

7. Tabagismo
$\square$ Fumante
Ex-fumante
Năo fumante

8. IMC: Peso:

Altura:

9. Avaliação cognitiva: MMSE:

10. Avaliação laboratorial: Ativ. PLA2: GSK:

11. Motivo do sedentarismo:

12. Participaria de um grupo de atividade física se fosse corvidado? 


\section{Anexo4}

\section{MINI-EXAME DO ESTADO MENTAL}

Brucki SMD e cols. Sugestöes para o uso do Mini-Exame do Estado Mental no Brasil. Arq Neuropsiquiatr 2003;61(3-B):777-781

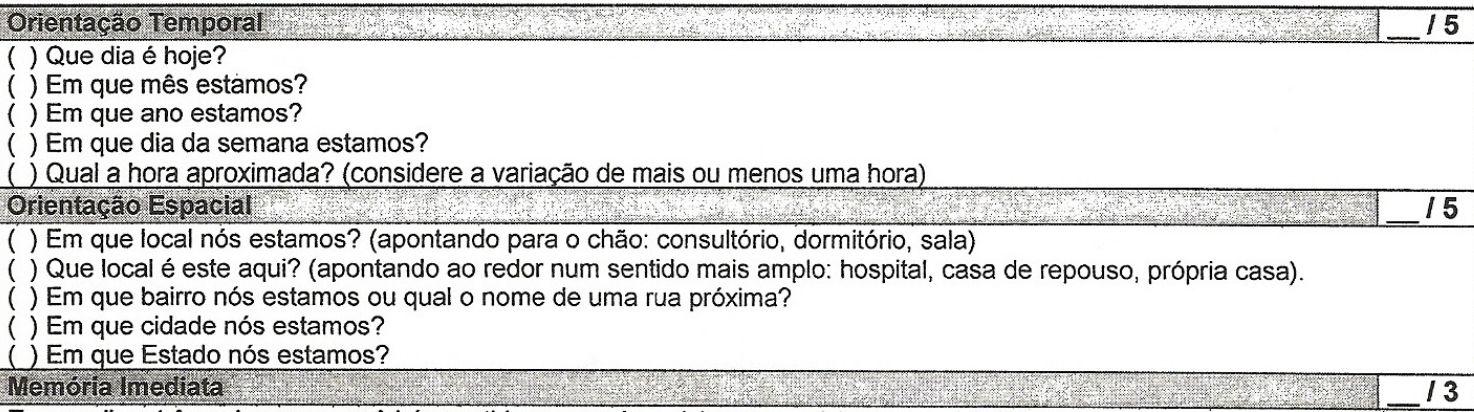

Eu vou dizer três palavras e você irá repeti-las a seguir: ( ) carro ( ) vaso, ( ) tijolo

Um ponto para cada palavra certa repetida na primeira vez, embora possa repeti-las até três vezes para o aprendizado.

Cálculo

Subtração de setes seriadamente: ( ) 100-7, ( ) 93-7, ( ) 86-7, ( ) 79-7, ( ) 72-7

Se houver erro, corrija-o e prossiga. Considere correto se o examinado se auto-corrigir.

Evocaçáo das Palavras

Pergunte quais as palavras que o sujeito acabara de repetir ( ) carro () vaso () tijo

Nomeação

Peça para o sujeito nomear dois objetos mostrados: ( ) relógio, ( ) caneta

Repeticăo

Vou lhe dizer uma frase e quero que você repita depois de mim: "Nem aqui, nem ali, nem lá".

Dê um ponto somente se a repetição for perfeita.

Comando

( ) Pegue este papel com a mão direita, ( ) dobre-o ao meio e ( ) coloque-o no chão

Se o sujeito pedir ajuda no meio da tarefa não dê dicas.

Leitura

Mostre a frase escrita "FECHE OS OLHOS" e peça para o indivíduo fazer o que está sendo mandado.

Não auxilie se pedir ajuda ou se só ler a frase sem realizar o comando.

Frase $\quad$ Pecol 11

Peça ao indivíduo para escrever uma frase. Se não compreender, ajude com: "alguma frase que tenha começo, meio e fim; alguma coisa que aconteceu hoje; alguma coisa que queira dizer". Não são considerados erros gramaticais ou ortográficos. Cópia do Desenho

Mostre o modelo e peça para fazer o melhor possivel.

Considere apenas se houver 2 pentágonos interseccionados formando uma figura de quatro lados.

- Escores de Corte para Diagnóstico de Demência

Consenso da Academia Brasileira de Neurologia para Diagnóstico de Doença de Alzheimer no Brasil (Arq Neuropsiquiatr 2005;63(3-A):713-9)

\begin{tabular}{|l|l|c|c|c|}
\hline \multicolumn{1}{|c|}{ Escolaridade } & Corte & Sensibilidade & Especificidade & Referencia \\
\hline Analfabetos & $19 / 20$ (caso/não caso) & $80 \%$ & $71 \%$ & Arq Neuropsiquiatr 1998;56:605-612 \\
\hline Alrabetizados & $23 / 24$ (caso/não caso) & $77,8 \%$ & $75,4 \%$ & Arq Neuropsiquiatr 1998;56:605-612 \\
\hline Escolariaade $\geq 8$ anos & $26 / 27$ (caso/não caso) & $80 \%$ & $95,6 \%$ & Arq Neuropsiquiatr 1994;52:1-7 \\
\hline
\end{tabular}

\section{- Escores de Corte para Rastreio de Demência}

Consenso da Academia Brasileira de Neurologia para Diagnóstico de Doença de Alzheimer no Brasil (Arq Neuropsiquiatr 2005;63(3-A):713-9)

$\Rightarrow$ Sugerimos o uso de outros instrumentos para confirmação de perda cognitiva em indivíduos com escores abaixo das médias e/ou medianas obtidas na adaptação publicada em 2003 por Brucki e cols.

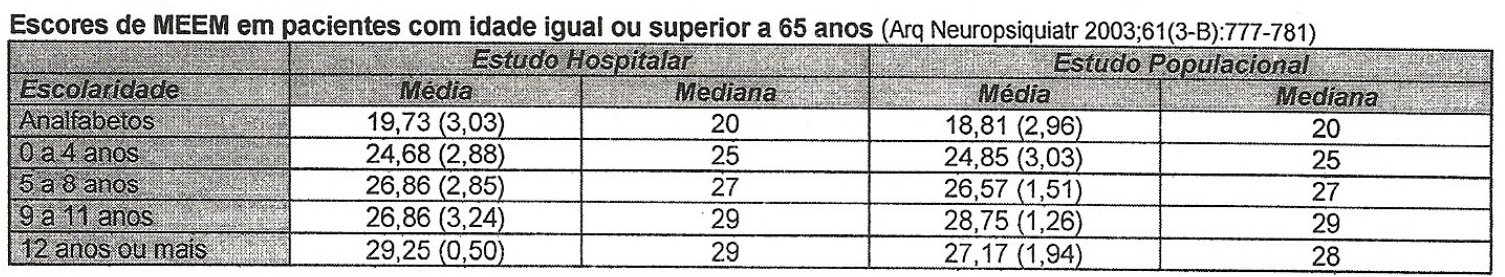




\section{Anexo 5}

Escala de Depressão Geriátrica de Yesavage - versão reduzida (GDS-15).

1. Você está satisfeito com a sua vida? (não)

2. Você deixou de lado muitos de suas atividades e interesses? (sim)

3. Você sente que sua vida está vazia? (sim)

4. Você sente-se aborrecido com freqüência? (sim)

5. Está você de bom humor na maioria das vezes? (não)

6. Você teme que algo de ruim Ihe aconteça? (sim)

7. Você se sente feliz na maioria das vezes? (não)

8. Você se sente freqüentemente desamparado? (sim)

9. Você prefere permanecer em casa do que sair e fazer coisas novas? (sim)

10. Você sente que tem mais problemas de memória que antes? (sim)

11. Você pensa que é maravilhoso estar vivo? (não)

12. Você se sente inútil? (sim)

13. Você se sente cheio de energia? (não)

14. Você sente que sua situação é sem esperança? (sim)

15. Você pensa de que a maioria das pessoas estão melhores do que você? (sim)

$0=$ quando resposta for diferente do exemplo do parênteses.

$1=$ quando resposta for igual ao exemplo do parênteses.

Contagem máxima de GDS = 15

Total $>5=$ suspeita de depressão.

Fountoulakis KN, Tsolaki M, lacovides A, Yesavage J,

O'Hara R, Kazis A, et al. The validation of the short

form of the geriatric depression scale (GDS) in

Greece. Aging (Milano) 1999;11(6):367-72.

Almeida OP, Almeida SA. Confiabilidade da versão

brasileira da escala de depressão em geriatria (GDS)

versão reduzida. Arq Neuropsiquiatr

1999;57(2B):421-6. 


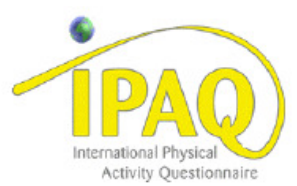

\section{QUESTIONÁRIO INTERNACIONAL DE ATIVIDADE FÍSICA - VERSÃO CURTA -}

Nome:

Data: $I^{\prime} \longrightarrow$ Idade : Sexo: F ( ) M ( )

Nós estamos interessados em saber que tipos de atividade física as pessoas fazem como parte do seu dia a dia. Este projeto faz parte de um grande estudo que está sendo feito em diferentes países ao redor do mundo. Suas respostas nos ajudarão a entender que tão ativos nós somos em relação à pessoas de outros países. As perguntas estão relacionadas ao tempo que você gasta fazendo atividade física na ÚLTIMA semana. As perguntas incluem as atividades que você faz no trabalho, para ir de um lugar a outro, por lazer, por esporte, por exercício ou como parte das suas atividades em casa ou no jardim. Suas respostas são MUITO importantes. Por favor responda cada questão mesmo que considere que não seja ativo. Obrigado pela sua participação!

Para responder as questões lembre que:

> atividades físicas VIGOROSAS são aquelas que precisam de um grande esforço físico e que fazem respirar MUITO mais forte que o normal

$>$ atividades físicas MODERADAS são aquelas que precisam de algum esforço físico e que fazem respirar UM POUCO mais forte que o normal

Para responder as perguntas pense somente nas atividades que você realiza por pelo menos 10 minutos contínuos de cada vez.

1a Em quantos dias da última semana você CAMINHOU por pelo menos 10 minutos contínuos em casa ou no trabalho, como forma de transporte para ir de um lugar para outro, por lazer, por prazer ou como forma de exercício?

dias por SEMANA

( ) Nenhum

1b Nos dias em que você caminhou por pelo menos 10 minutos contínuos quanto tempo no total você gastou caminhando por dia?

horas: Minutos:

2a. Em quantos dias da última semana, você realizou atividades MODERADAS por pelo menos 10 minutos contínuos, como por exemplo pedalar leve na bicicleta, nadar, dançar, fazer ginástica aeróbica leve, jogar vôlei recreativo, carregar pesos leves, fazer serviços domésticos na casa, no quintal ou no jardim como varrer, aspirar, cuidar do jardim, ou qualquer atividade que fez aumentar CENTRO COORDENADOR DO IPAQ NO BRASIL- CELAFISCS INFORMAÇÖES ANÁLISE, CLASSIFICAÇÄO E COMPARAÇÄO DE RESULTADOS NO BRASIL Tel-Fax: - 011-42298980 ou 42299643. E-mail: celafiscs@celafiscs.com.br Home Page: www.celafiscs.com.br IPAQ Internacional: www.ipaq.ki.se 
moderadamente sua respiração ou batimentos do coração (POR FAVOR NÃO INCLUA CAMINHADA)

dias por SEMANA

( ) Nenhum

2b. Nos dias em que você fez essas atividades moderadas por pelo menos 10 minutos contínuos, quanto tempo no total você gastou fazendo essas atividades por dia?

horas: Minutos:

3a Em quantos dias da última semana, você realizou atividades VIGOROSAS por pelo menos 10 minutos contínuos, como por exemplo correr, fazer ginástica aeróbica, jogar futebol, pedalar rápido na bicicleta, jogar basquete, fazer serviços domésticos pesados em casa, no quintal ou cavoucar no jardim, carregar pesos elevados ou qualquer atividade que fez aumentar MUITO sua respiração ou batimentos do coração.

dias por SEMANA

( ) Nenhum

3b Nos dias em que você fez essas atividades vigorosas por pelo menos 10 minutos contínuos quanto tempo no total você gastou fazendo essas atividades por dia?

horas: Minutos:

Estas últimas questões são sobre o tempo que você permanece sentado todo dia, no trabalho, na escola ou faculdade, em casa e durante seu tempo livre. Isto inclui o tempo sentado estudando, sentado enquanto descansa, fazendo lição de casa visitando um amigo, lendo, sentado ou deitado assistindo TV. Não inclua o tempo gasto sentando durante o transporte em ônibus, trem, metrô ou carro.

4a. Quanto tempo no total você gasta sentado durante um dia de semana? horas minutos

4b. Quanto tempo no total você gasta sentado durante em um dia de final de semana? horas __ minutos

\section{PERGUNTA SOMENTE PARA O ESTADO DE SÃO PAULO}

5. Você já ouviu falar do Programa Agita São Paulo? ( ) Sim ( ) Não

6.. Você sabe o objetivo do Programa? ( ) Sim ( ) Não

CENTRO COORDENADOR DO IPAQ NO BRASIL- CELAFISCS -

INFORMAÇŌES ANÁLISE, CLASSIFICAÇÃO E COMPARAÇÃO DE RESULTADOS NO BRASIL

Tel-Fax: - 011-42298980 ou 42299643. E-mail: celafiscs@celafiscs.com.br

Home Page: www.celafiscs.com.br IPAQ Internacional: www.ipaq.ki.se 


\section{Classificação do IPAQ}

Sedentário - Não realiza nenhuma atividade física por pelo menos 10 minutos contínuos durante a semana;

Insuficientemente Ativo - Consiste em classificar os individuos que praticam atividades físicas por pelo menos 10 minutos continuos por semana, porém de maneira insuficiente para ser classificado como ativos. Para classificar os individuos nesse critério, são somadas a duração e a freqüencia dos diferentes tipos de atividades (caminhadas + moderada + vigorosa). Essa categoria dividese em dois grupos:

Insuficientemente Ativo A - Realiza 10 minutos contínuos de atividade física, seguindo pelo menos um dos criterios citados: freqüencia - 5 dias/semana ou duração - 150 minutos/semana;

Insuficientemente Ativo $B$ - Não atinge nenhum dos criterios da recomendação citada nos individuos insuficientemente ativos A;

Ativo - Cumpre as seguintes recomendaçôes: a) atividade física vigorosa $-\geq 3$ dias/semana e $\geq 20$ minutos/sessão; b) moderada ou caminhada $-\geq 5$ dias/semana e $\geq 30$ minutos/sessão; c) qualquer atividade somada: $\geq 5$ dias/semana e $\geq 150 \mathrm{~min} / \mathrm{sema}$ na;

Muito Ativo - Cumpre as seguintes recomendaçoes: a) vigorosa $-\geq 5$ dias/semana e $\geq 30 \mathrm{~min} /$ sessão; b) vigorosa $-\geq 3$ dias/ semana e $\geq 20 \mathrm{~min} /$ sessão + moderada e ou caminhada $\geq 5$ dias/ semana e $\geq 30 \mathrm{~min} /$ sessão. 


\section{Anexo 08}

\section{Atividade da GSK3}

Para a determinação de GSK 3 foram coletados $15 \mathrm{~mL}$ de sangue periférico em tubo contendo anticoagulante citrato de sódio para a separação das plaquetas.

\section{Separação e lavagem das Plaquetas:}

Foram coletados $40 \mathrm{~mL}$ de sangue em quatro tubos com capacidade de $10 \mathrm{~mL}$, contendo anticoagulante citrato de sódio $0,106 \mathrm{~mol} / \mathrm{L}$. Adicionado em cada tubo $1 \mathrm{~mL}$ de ACD-NH. Os tubos foram homogeneizados delicadamente por inversão e centrifugados durante 15 minutos a $1600 \mathrm{rpm}$ a $20^{\circ} \mathrm{C}$. A seguir, os sobrenadantes (Plasma Rico em Plaquetas - PRP) foram transferidos para outro tubo com capacidade de $50 \mathrm{~mL}$ (tipo falcon) e o pH ajustado para 6,5 com ACD-NH. O PRP foi, então, transferido para 4 tubos de poliestireno (4 a 5 $\mathrm{mL} /$ tubo) e centrifugados durante 10 minutos a $2400 \mathrm{rpm}$ à $20^{\circ} \mathrm{C}$. O sobrenadante foi removido cuidadosamente por inversão, adicionado ao pellet $2,5 \mathrm{~mL}$ de solução de lavagem.

Após descanso de 10 minutos, as plaquetas foram homogeneizadas cuidadosamente com uma pipeta Pasteur até total diluição e então adicionou-se mais 2,5 $\mathrm{mL}$ de solução de lavagem. A mistura foi centrifugada por 8 minutos a $2400 \mathrm{rpm}$, o sobrenadante foi removido cuidadosamente, e o "pellet" foi ressuspendido com $0,5 \mathrm{~mL}$ de tris-sacarose, homogeneizando com a pipeta. As plaquetas em tris-sacarose foram armazenadas em 4 criotubos com $0,5 \mathrm{~mL}$ e mantidas em freezer $-70^{\circ} \mathrm{C}$ para posterior determinação da concentração de proteínas e atividade da $\mathrm{PLA}_{2}$.

\section{Determinação de proteínas}

As proteínas foram quantificadas utilizando o kit Bio-Rad DC Protein assay (Bio-Rad Hercules, CA) que é um ensaio colorimétrico para a deteminação de proteínas, baseado no método de Lowry (Lowry et al., 1951), modificado para ser compatível com detergentes utilizados no preparo da amostra. O ensaio consiste na reação de proteínas com uma solução alcalina de tartarato de cobre (Reagente A) e com o reagente de Folin (1,2naphthoquinone-4-sulfonate) (Reagente B). Como no ensaio de Lowry, existem duas etapas que levam ao desenvolvimento da cor: a reação entre proteínas e o cobre em um meio alcalino, e a subseqüente ligação do reagente de Folin às proteínas tratadas com cobre 
(Lowry et al., 1951). Quando o reagente de Folin liga-se a essas proteínas, ele é reduzido pela perda de 1, 2 ou 3 átomos de oxigênio, e muda a cor do amarelo para um azul característico, cuja absorbância é lida entre 405 e 750 nm (Peterson,1979).

Para a determinação das proteínas totais, foi utilizada uma curva padrão de proteínas utilizando-se albumina de soro bovino (bovine serum albumin ou BSA; Sigma-Aldrich), nas seguintes concentrações: $0,1 \mathrm{mg} / \mathrm{mL}, 0,2 \mathrm{mg} / \mathrm{mL}, 0,5 \mathrm{mg} / \mathrm{mL}, 1,0 \mathrm{mg} / \mathrm{mL}$ e $1,5 \mathrm{mg} / \mathrm{mL}$.

O ensaio foi realizado em microplacas de 96 poços (em temperatura ambiente), onde foi pipetado $25 \mu \mathrm{L}$ do Reagente $\mathrm{A}, 5 \mu \mathrm{L}$ do padrão de proteínas de BSA nas seis diferentes concentrações ou $5 \mu \mathrm{L}$ das amostras ou branco (tris-sacarose) e $200 \mu \mathrm{L}$ do Reagente B. Após incubação de 15 min em temperatura ambiente em um Agitador de placas (WallacPerkinElmer, Boston, MA), as absorbâncias das amostras foram lidas em um Leitor de microplacas (Spectracount; Packard, Meriden, CT) a $680 \mathrm{~nm}$. Todas as determinações dos níveis de proteínas foram realizadas em triplicatas.

\section{Determinação de biomarcadores pelo método xMAP-Luminex:}

O principio desta nova tecnologia é a habilidade de medir múltiplos analitos em um único ensaio. Com a tecnologia do LUMINEX $\mathrm{XMAP}^{\circledR}$ reações moleculares ocorrem na superfície de microesferas marcadas internamente com intensidades diferentes de dois fluoróforos (vermelho e infravermelho), permitindo a obtenção de mais de 100 microesferas distintas com combinações de diferentes intensidades dos dois fluoróroros. Como cada microesfera carrega uma "assinatura" única a detecção do sistema XMap pode identifica-la, permitindo diversas análises (mais de 100) em uma única reação.

As microesferas agem como carreadores moleculares, tais como, anticorpo, oligonucleotídeos, peptídeos ou receptores que capturam a amostra e são então marcadas com um marcador fluorescente que se liga ao complexo microesfera-amostra. As reações são realizadas em placas de 96 wells e em seguida as amostras são injetadas no aparelho e alinhadas em uma fila única e desta maneira passam através de dois lasers. Um laser ilumina a cor interna da microesfera identificando-a e o segundo excita a cor na sua superfície. Os sinais emitidos pelas cores são capturados por sistema óptico, o sinal é digitalizado, e processado em tempo real, quantificando os dados para cada reação.

Para a metodologia utilizando o Luminex foram utilizados kits da Invitrogen (CA USA), que se baseiam na utilização de anticorpos acoplados a microesferas anti GSK-3ß(Total) e anti 
GSK-3ß[pS9]. Resumidamente, os anticorpos marcados juntamente com as amostras e padrões são pipetados em uma microplaca com filtro e incubadsos por 2 horas, tempo necessário para a ligação das amostras aos anticorpos, após lavagem adiciona-se os anticorpos de detecção para cada uma das isoformas e incuba-se novamente por 1 hora. Segue-se uma lavagem para remoção dos anticorpos em excesso e adiciona-se o conjugado (anti rabbit R-Phicoerythrin -RPE). Após incubação de 30 minutos, lava-se novamente a placa e realiza-se a análise das microesferas no equipamento Luminex. A monitorização das propriedades espectral das microesferas e a quantidade de fluorescência associada ao RPE, nos permite determinar a concentração das isoformas de GSK-3ß 